NASACONTRACTOR REPORT

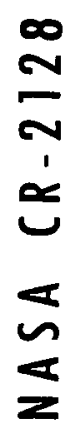

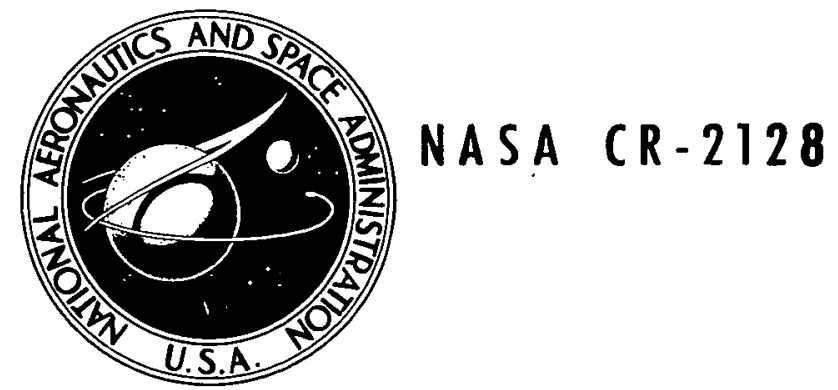

\title{
AN EXPERIMENTAL STUDY OF SLOT INJECTION
}

INTO A SUPERSONIC STREAM

by Michael Kenworthy and Joseph A. Schetz

Prepared by

VIRGINIA POLYTECHNIC INSTITUTE AND STATE UNIVERSITY

Blacksburg, Va. 24060

for Langley Research Center

NATIONAL AERONAUTICS AND SPACE ADMINISTRATION - WASHINGTON, D. C. • JANUARY 1973 


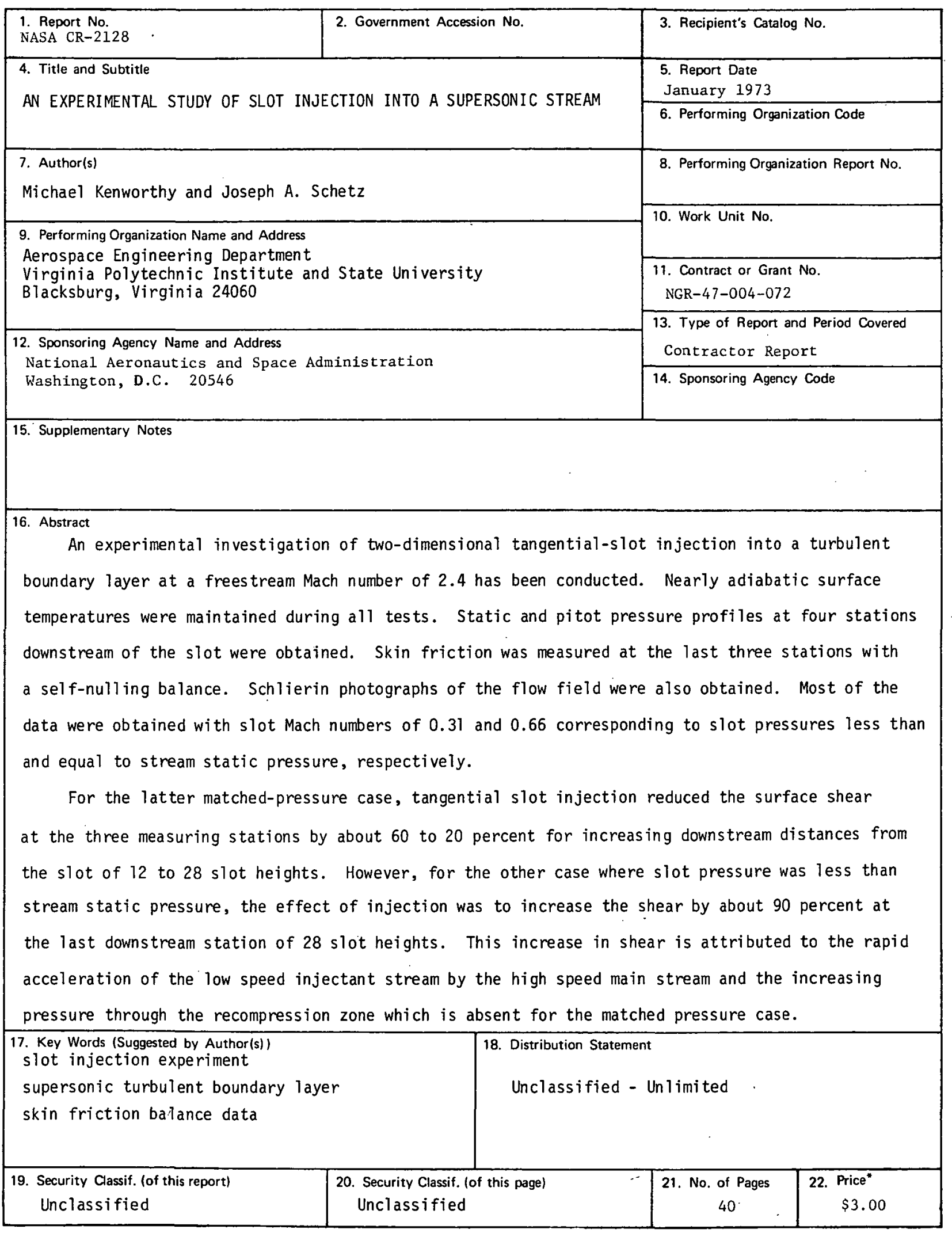

"For sale by the National Technical Information Service, Springfield, Virginia 22151 
Page

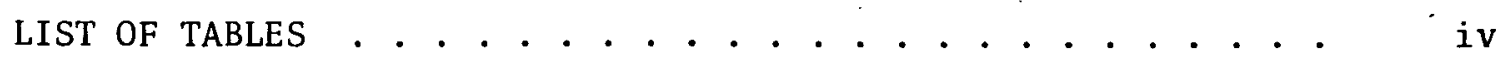

LIST OF FIGURES . . . . . . . . . . . . . . . . . . . . v v

LIST OF SYMBOLS ........................ . . . . . . . vi

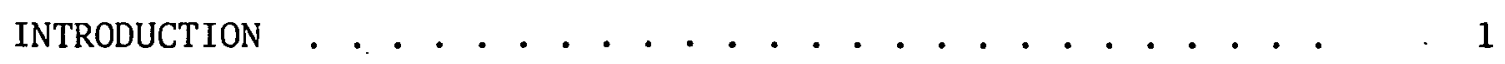

EXPERIMENTAL APPARATUS .......................... 2

A. WIND TUNNEL ..................... 2

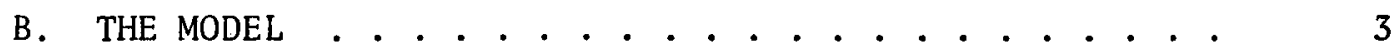

C. PROBES ....................... 4

Pitot Probes ............... . . 5

Cone Static Probes . . . . . . . . . . . 5

D. SKIN FRICTION : . . . . . . . . . . . . 5

E. OPTICS ...................... 6

TEST PROCEDURE ............................. 6

DATA REDUCTION ........................... 6

A. PRESSURES ........................ 6

B. MACH NUMBER PROFILES .............. . . . 6

C. SKIN FRICTION ................. 7

RESULTS ................................. 7

A. FLOW VISUALIZATION

B. PROFILE MEASUREMENTS . . . . . . . . . . . . . . . . . 8

C. WALL SHEAR .................. . . . 9

MOMENTUM INTEGRAL ANALYSIS OF THE DATA . . . . . . . . . 10

DISCUSSION ............................. 11

APPENDIX A (ERROR ANALYSIS) . . . . . . . . . . . 11

Pitot Pressure . . . . . . . . . . . . . . 11

Cone Static ......................... 11

Normalized Pressures ............. . . . 11

Vertical Position .............. 12

Pressure Ratios . . . . . . . . . . . . . . 12

Mach Number Profiles . . . . . . . . . . . 12

Skin Friction ................. . . . 12

REFERENCES .............................. 12 


\section{LIST OF TABLES}

TABLE NO.

1. A SURVEY OF RESEARCH ON TANGENTIAL INJECTION $\quad$ • . . . . . . 14

A-1. ESTIMATE OF ERRORS IN MEASURED AND CALCULATED QUANTITIES .. 16 


\section{LIST OF FIGURES}

Figure

$\underline{\text { Page }}$

1 Schematic of Tangential Injection Flow Field . . . . . 17

2 Schematic of Mode1 . . . . . . . . . . . . 18

3 Spanwise Static Pressure Distribution in Slot . . . . . 19

4 Instrumented Test Section . . . . . . . . . . . 20

5 Photographs of Apparatus . . . . . . . . . . . . 21

6 Schematic of Cone Static Pressure Probe . . . . . . . 22

7 Schematic of Skin Friction Balance . . . . . . . . 23

8 Photographs of Skin Friction Balance . . . . . . . . . 24

9 Typical Skin Friction Balance Calibration Curve . . . . 25

10 Streamwise Pressure Distribution . . . . . . . . . 26

11 Schlieren Photographs . . . . . . . . . . . . 27

12 Spark Schlieren Photographs . . . . . . . . . . . 28

13 Static Pressure Profile at Station Two, High Mass Flow Rate ...................... . . 29

14 Mach Number Profiles, Low Mass Flow . . . . . . . . 30

15 Mach Number Profiles, High Mass Flow . . . . . . . . . 31

16 Streamwise Shear Distribution . . . . . . . . . 32

17 Schlieren Photographs for Underexpanded Injection . . . 33

18 Shear vs. Mass Flux Ratio . . . . . . . . . . . 34

19 Integral Boundary Layer Thickness-Low Mass Flow . . . . 35

20 Wall Shear from Momentum Integra1-Low Mass Flow . . . . 36 


\begin{tabular}{|c|c|}
\hline a & Slot height \\
\hline M & Mach number \\
\hline $\mathrm{p}$ & Pressure \\
\hline $\mathrm{p}_{\mathrm{o}}$ & Stagnation pressure \\
\hline $\mathrm{p}_{\mathrm{o}}^{\prime}$ & Pitot pressure \\
\hline $\mathrm{p}_{\mathrm{c}}$ & Cone pressure \\
\hline $\operatorname{Re}$ & Reynolds' number \\
\hline $\mathrm{T}$ & Temperature \\
\hline $\mathrm{U}$ & Streamwise velocity \\
\hline $\mathbf{x}$ & Streamwise distance \\
\hline$y$ & Normal distance \\
\hline $\mathrm{z}$ & Spanwise distance \\
\hline$\tau_{w}$ & Wa11 shear \\
\hline$\rho$ & Density \\
\hline$\eta$ & Cooling effectiveness \\
\hline$\delta *$ & Displacement thickness \\
\hline$\theta$ & Momentum thickness \\
\hline \multicolumn{2}{|c|}{ Subscripts } \\
\hline 1 & Free stream ahead of slot \\
\hline 2 & Free stream after slot interaction \\
\hline$s$ & Slot conditions \\
\hline w & Wall conditions \\
\hline$t$ & Reservoir conditions for main flow \\
\hline
\end{tabular}


AN EXPERIMENTAL STUDY OF SLOT INJECTION

\author{
INTO A SUPERSONIC STREAM
}

By Michael Kenworthy and Joseph A. Schetz

Virginia Polytechnic Institute and State University

\title{
INTRODUCTION
}

The tangential injection of a secondary stream into a primary flow by means of a wall slot is a problem of current interest since there are a number of promising applications on the horizons of technology. For example, injection of a low kinetic and/or thermal energy stream would serve as a means of reducing skin friction and heat transfer. On the other hand, tangential injection of a high kinetic energy stream can be expected to prevent separation by supplying the boundary layer with sufficient energy to overcome unfavorable pressure gradients such as those on inlets of jet engines. Proposals have been made to combine the advantages of this unique flow field with a fuel injection system for supersonic combustion in hypersonic engines where the problems of separation and cooling are severe. That is, by utilizing successive injection slots, it would seem possible to alleviate separation on the inlet and cool internal surfaces as well as provide for fuel injection.

The flow is shown schematically in Fig. 1. It is basically a two-dimensional shear flow, i.e., a simple velocity discontinuity; however, it is bounded on one side and therefore offers some very interesting problems in analysis. To date, the experimental research conducted in this area for a supersonic primary flow has been exploratory since, in each study, only limited aspects of the flow field have been measured; see Table I, Refs. (1)-(6), for a representative sample. For example, Cary and Hefner (6) carried out experiments varying a wide range of parameters such as slot height, mass flow ratio, and temperature ratio. However, the physical arrangement included end plates to insure two dimensionality which allowed no flow visualization. The primary measurements were skin friction and equilibrium wall temperature. On the other hand, Schet $z$ and Gilreath $(4,5)$ investigated subsonic and supersonic injection into a supersonic primary stream by means of an interferometer. This led to density profiles and wall pressure distributions as the only quantitative data. The present work was planned to provide a more complete and detailed description of the entire flow field for the case with a supersonic primary flow and a subsonic injectant.

Due to the nature of the work and facilities involved, parameters such as slot height, set at $0.635 \mathrm{~cm}$, and the free stream Mach number of 2.4 were held constant throughout these experiments. The lip thickness $(0.0127 \mathrm{~cm})$ was set at the minimum achievable value to match as closely 
as possible an idealized shear flow. The main parameter varied was the injected mass flux which was normalized by the free stream mass flux. Two subsonic injectant flow rates were selected to investigate first the case of overexpanded injection, $\left(\frac{\rho_{s} u_{s}}{\rho_{1} u_{1}}\right)=0.0764$, and then the case of matched pressure conditions at the slot, $\left(\frac{\rho_{s} u_{s}}{\rho_{1} u_{1}}\right)=0.02027$. This gave Mach numbers in the slot of 0.31 and 0.66 respectively.

Following this, static and pitot pressure surveys were made at four stations downstream of the slot, and Mach profiles were obtained. Finally, direct wall shear measurements were made at the last three stations using a self-nulling skin friction balance. Also, the flow field was documented with a number of shadowgraph, schlieren, and spark schlieren photographs which provided a great detail of qualitative insight into this complicated process. It should also be noted that this work dealt with a flow in which the boundary layer thickness was of the same order of magnitude as the slot height.

The test conditions for these experiments were chosen to give relatively long, wel1 regulated runs. The total reservoir pressure was set at $4.22 \mathrm{x}$ $10^{4} \mathrm{Kg} / \mathrm{m}^{2}$ with temperature of the reservoir at $286^{\circ} \mathrm{K}$. These conditions gave a free stream unit Reynolds number of $4.25 \times 10^{6}$ per meter. This is a fairly high Reynolds number and, as would be expected, the approach boundary layer was observed to be turbulent. The runs were of the order of 10 to 15 seconds which was sufficient to cover response times of the flow and instruments. Since the recovery temperature of the air of both the free stream and injectant flows was very nearly room temperature, the flow was treated as adiabatic.

In the next section, the experimental apparatus, including the wind tunnel, the mode1, the probes, the skin friction balance, the instrumentation, and the optical equipment, is described in detail. The succeeding sections outline the test procedure, data reduction and experimental results. An error analysis is given in Appendix A.

\section{EXPERIMENTAL APPARATUS}

A. WIND TUNNEL

These experiments were performed in the $23 \mathrm{~cm} \times 23 \mathrm{~cm}$ supersonic wind tunnel at VPI\&SU. This tunnel was designed and originally constructed at the Langley Aeronautical Laboratory. In 1958 the tunnel was purchased by VPI and, after being reconstructed, was put into operation in 1963. During recent years, several modifications have been introduced to update the tunnel's capabilities as a precision research instrument.

The facility is of an intermittent, blow-down type with interchangeable 
contoured nozzles. However, for this particular project a special nozzle arrangement was constructed to serve as the model as well as nozzle. The air is pumped by eight Ingersol1 Rand, Mode1 90, reciprocating compressors with a total capacity of $800 \mathrm{hp}$. The air is then stored in sixteen storage tanks with a total volume 79.3 cubic meters. At present, the maximum pressure obtainable by the compressors is $1.05 \times 10^{5} \mathrm{Kg} / \mathrm{m}^{2}$ in these tanks. The tunnel is activated by a quick opening butterfly valve with a variable speed control.

The settling chamber contains a perforated transition cone, several dampening screens, and probes to measure stagnation pressure and temperature. The air is then accelerated through a Laval type nozzle block, passing through a test section, then a diffuser and is dumped into the atmosphere.

\section{B. THE MODEL}

As mentioned in the last section, the model was a modified version of the interchangeable contoured nozzles generally used in this wind tunnel (see Fig. 2). The streamline normally produced at the axis of a two-dimensional, symmetric supersonic nozzle is replaced by a solid surface. Just beyond the last expansion wave in the nozzle, the surface steps down to form the slot. The reason for the construction of this special nozzle was three-fold. First, this configuration allows ample room for a plenum chamber for the injected gas where it can be uniformly distributed and straightened insuring a uniform, 2-D injected flow. Second, for optical reasons it was advantageous to place the injection slot above the usual tunnel floor since the windows, even though rather large, were designed to study the flow in the center of the tunnel. Third, use was made of a highly instrumented plate which was to be located directly downstream of the slot, and this could be conveniently done only by using the configuration shown.

The block for the upper half of the nozzle was selected to give a Mach number of approximately 2.4. The bottom of the nozzle was then designed in four sections. The first two are of little importance except that they were designed to be compatible with the upper half (i.e. for $M=2.4$ ). Also the second section, which was designated the dummy section, had three stations so that a spanwise survey of static pressure could be made upstream of the injection station to insure the experiment was, in fact, two dimensional.

The third section was given the most consideration due to the fact a uniform 2-D flow had to be established from a pipe which is essentially a point source. In order to achieve the desired results, the flow of air was introduced to the bottom of this section through a header which was fabricated from a $5 \mathrm{~cm}$ pipe with holes drilled in such a manner as to provide more escape area toward the ends of the header since the air entered the header exactly in the middle through a perpendicular $1.9 \mathrm{~cm}$ pipe. For the under-expanded injection tests, a new header with dual inlet ports was constructed to accommodate the necessary increased flow 
rate. The flow then passed through a flow straightener which measured $5 \mathrm{~cm}$ long in the flow direction. This was constructed by placing about four hundred, $5 \mathrm{~cm}$ pieces of plastic straws between wire screens. This arrangement gave a very uniform flow as shown by the spanwise static pressure distributions in Figure 3.

The final section of the nozzle was a wall made of polished 304 stainless steel which was instrumented with static pressure taps and thermocouples in both the streamwise and spanwise directions. The static pressure taps were $0.787 \mathrm{~mm}$ in diameter and the thermocouples were $0.25 \mathrm{~mm}$ copper-constantan wire press fitted on the plate's surface. The locations of these and their relative position to the slot is shown in Figure 4. Also included in this figure are the locations of the four stations where the vertical measurements were taken. This instrumented plate was followed by a $1.27 \mathrm{~cm}$ steel plate ramp in order to bring the flow into the diffuser. This is seen in the far right of Fig. 5a.

In order to probe the boundary layer and shear layer, a traversing mechanism was built which operated from the bottom of the instrumented wal1. The mechanism was basically made of a one rpm motor which moved a rack gear on which the probes were mounted. Ports were provided through which the probes were inserted and attached to the traversing mechanism. These were located 3.81 centimeters to either side of the wall centerline. A three turn precision linear potentiometer was connected to the one rpm motor to determine the position of the probes at any given time. The time to traverse one way across the boundary and shear layers was on the order to 5-7 seconds.

A photograph of the entire test arrangement is given in Fig. 5a. The main tunnel flow is from left to right, the slot opening is visible along the tunnel centerline and $a^{\prime}$ probe is shown in position for traversing.

\section{PROBES}

A11 pressures were read using strain gauge transducers which were calibrated within $\pm .15 \%$ of their individual full scale ranges. Transducer outputs were read on Hewlett-Packard strip chart recorders with a microvolt sensitivity $\pm .1 \%$ full scale.

The response times of the combination of probes and transducers was determined by positioning a probe at a fixed height, taking a measurement, and comparing with a measurement obtained while traversing at the same height. It was determined that the response times were undetectable within the limits of the experimental error.

Two sets of probes were used for these experiments. The longer set as pictured in Fig. 5b was used to reach the first station downstream of the injection slot due to physical limitations of the model. The short set of probes was used for the three remaining stations. 
Also of concern was the aerodynamic loading on these probes and any resulting deflections, especially for the longer probes used at the first station. A previous set of experiments using similar probes showed a constant deflection of $0.0763 \mathrm{~cm}$. The probes were therefore modified to include $0.546 \mathrm{~cm}$ stainless steel shanks, a brace from shank to probe tip, and $a$ fin to reduce any moments arising from angle of yaw, hence inducing instability (see Fig. 5b). Then, a photographic study of probe deflection was conducted. First, a probe was placed in the tunnel at a set height and a shadowgraph was taken. The supersonic flow was introduced and another shadowgraph was taken. The results of comparisons of these sets of pictures showed deflection was less than $\pm 0.0051 \mathrm{~cm}$.

Pitot probes.--The pitot probes were made by flattening $0.318 \mathrm{~cm}$ 0.D. stainless steel circular tubing to a rectangular cross section at the tip. The opening on each probe was $0.0254 \mathrm{~cm} \times 0.318 \mathrm{~cm}$ with a 1 ip thickness of approximately $0.0203 \mathrm{~cm}$.

Cone static probes.--The cone static probes were $10^{\circ}+2^{\prime}$ semivertex angle brass cones with base diameter of $0.157 \mathrm{~cm}$ soldered to $0.160 \mathrm{~cm}$ stainless steel tubing. The tips were precision ground and extreme care had to be exercised in order to keep the vertex at its assigned value. Four $0.033 \mathrm{~cm}$ ports were drilled perpendicular to the cone's surface approximately three quarters of the way back from the tip at $90^{\circ}$ intervals around the circumference. The four ports lead to a common chamber, so that recorded pressures were the average pressures and angle of attack effects were reduced to a minimum. A drawing of the probe tip is given in Figure 6 .

\section{SKIN FRICTION BALANCE}

The skin friction balance used in these experiments is described in detail in Ref. (7). Essentially, the balance is designed as a nulltype device in that the deflections of the floating head element due to shear are returned to zero by a servodrive mechanism. The balance was designed to operate in a horizontal position, however in these experiments, the unit was used in an upright mode. In the former position gravity was used to supply a small amount of tension to the servomechanism. Here, the problem was solved with a small spring opposed to the spring connecting the balance arm and servodrive. Also of note, is the fact that the balance did not incorporate the cooling mechanism described in Ref. (7). The linear variable differential transformer (LVDT) is excited by a carrier amplifier which is in turn amplified by an amplifier which drives the servomotor. The servomotor returns the LVDT to zero and at the same time activates a potentiometer whose output is recorded on the strip recorders indicating the shear load. In order to relate the output on the recorders to the shear loads incurred, a calibration arm was added on the balance arm.

A schematic and photograph of this arrangement are shown in Figures 7 and 8. The floating head of the balance was made oblong in the lateral or spanwise direction in order to minimize the pressure gradient effects. The 
area of the floating element was $3.200 \mathrm{~cm}^{2}$, and the surface of the test section wall and floating head were flush well within $\pm 0.0025 \mathrm{~cm}$ for all stations.

\section{E. OPTICS}

The flow was photographed using three basic techniques, shadowgraph, schlieren, and spark schlieren. For the shadowgraph and schlieren pictures, a continuous collimated beam of light was passed through the test section using the PEK model $910 \mathrm{~L} . \mathrm{H}$. light source and PEK type 107 lens. The duration of these exposures was one millisecond. The spark schlieren was facilitated by the EGGG 54.9-11 Microflash at one microsecond and a Kodak Wratten Filter (no. 77A). A11 photographs were taken on Polaroid type 57 (ASA 3000) sheet film using a Graphlex camera. The windows of the test section were ground and polished to \pm 15 arc seconds which is of schlieren quality.

\section{TEST PROCEDURE}

1. Spanwise surveys were made upstream, in the slot, and downstream of the slot to assure two-dimensionality.

2. Streamwise surveys of the wall pressure were made for several different mass flow rates in the slot, and two were chosen for detailed study. Also schlieren and spark. schlieren photographs were made with no instrumentation in the tunnel.

3. Vertical profiles were then made of the pitot pressure and cone static pressure for each mass flow at each station.

4. Skin friction measurements were made at the last three stations, one for each mass flow in the slot. It was impossible to obtain a direct skin friction measurement at the first station due to physical limitations of the instrumented plate.

\section{DATA REDUCTION}

\section{A. PRESSURES}

Al1 recorded pressures were normalized by the instantaneous stagnation pressure in the settling chamber to minimize errors due to small total pressure variations throughout the run.

\section{B. MACH NUMBER PROFILES}

Once the pressure profiles were available, the Mach number profiles could be readily deduced from a ratio of cone static to stagnation pressure. Of course, this ratio can be written as

$$
\frac{\mathrm{p}_{\mathrm{c}}}{\mathrm{p}_{\mathrm{o}}^{\prime}}=\left[\frac{\mathrm{p}_{\mathrm{c}}}{\mathrm{p}}\right]\left[\frac{\mathrm{p}}{\mathrm{p}_{\mathrm{o}}}\right]\left[\frac{\mathrm{p}_{\mathrm{o}}}{\mathrm{p}_{\mathrm{o}}^{\prime}}\right] \text {, }
$$


all of which are functions of Mach number only. A plot of $\mathrm{p}_{\mathrm{c}} / \mathrm{p}_{\mathrm{d}}$ versus $M$ was then made. The quantity $\mathrm{pc}_{\mathrm{p}} \mathrm{p}$ was obtained from Ref. (8), and Ref. (9) was used for the remaining two ratios.

According to Ref. (8) the $10^{\circ}$ semivertex angle cone will retain an attached shock only for Mach numbers greater than 1.116. If the ratio of $\mathrm{pc} / \mathrm{po}_{\mathrm{j}}$ gave a Mach number less than 1.12, then, in order to calculate the true Mach number, one must make the boundary layer assumption, $\partial p / \partial y=0$, $\left(\frac{1}{\sqrt{\operatorname{Re}}}\right) \simeq 0$ since $\operatorname{Re}=4.25 \times 10^{6}$ per meter. Therefore the value of the normalized static pressure at the wall, $\mathrm{p}_{\mathrm{w}} / \mathrm{p}_{\mathrm{ot}}$ was used to approximate $\mathrm{p} /$ pot. Also, in this flow regime, $\frac{p_{o}}{p_{o t}}=\frac{p_{o}}{p_{o t}}$. Therefore the value $\frac{p_{w}}{p_{0}^{1}}=\frac{p}{p_{0}}$, which is a function of Mach number only, and Ref. (9) readily supplied the Mach number.

\section{SKIN FRICTION}

The skin friction was simply arrived at from the calibration curves which were obtained before and after runs at each station. A typical calibration curve is shown in Figure 9.

\section{RESULTS}

Tests were conducted at several injection mass flow rates. The great majority of the test runs and the detailed profile observations were made at two subsonic injection conditions selected to provide one case with overexpanded injection $\left(\mathrm{p}_{\mathrm{s}}<\mathrm{p}_{1}\right)$ and one case with matched pressure $\left(\mathrm{p}_{\mathrm{s}}=\mathrm{p}_{1}\right)$ injection. The streamwise wall pressure distributions resulting from these two conditions is shown in Fig. 10. The high mass flow, matched-pressure, case shows an essentially constant pressure distribution which is to be expected since no adjustment between the main and injectant streams is required at this condition. On the other hand, the low mass flow, overexpanded injection, case shows a strong adverse pressure gradient produced by the recompression region.

A total of over seventy individual, data taking tests were performed with many redundant observations to certify the repeatibility of the measurements.

\section{A. FLOW VISUALIZATION}

Schlieren and spark-schlieren photographs for the two main cases are given in Figs. 11 and 12. Pictures of this type are extremely helpful in understanding the qualitative aspects of the flow field as well as in interpreting the detailed profile measurements. It can be noted that the splitter plate boundary layer is approximately equal to the slot. height and that it 
is clearly turbulent.

For the over-expanded injection case shown in Figs. $11 \mathrm{~b}$ and $12 \mathrm{~b}$, one can clearly see the adjustment required at the injection station in order to match the static pressure on each side of the dividing streamline emanating from the slot lip. The higher pressure free stream turns through an expansion fan towards the wall, and the injectant stream is compressed. After a length equal to several slot heights, the free stream turns back parallel to the horizontal through a distributed recompression region.

In the matched-pressure case shown in Figs. 11a and 12a, the free stream proceeds in an essentially undisturbed direction as can be observed by tracing the outer edge of the splitter plate boundary layer along the outer edge of the mixing region downstream of the injection station.

A lip shock produced by viscous interactions near the lip of the finite thickness splitter plate is visible in both cases. For the low pressure case, it terminates the expansion fan, and for the matched pressure case, it is the only disturbance that is produced in the free stream. It is interesting to observe the curvature in this weak shock as it proceeds out from the lip through the vortical flow of the splitter plate boundary layer.

An additional, perhaps important, feature of the flow is the wake produced by the slot lip which can be clearly discerned in Figs. 12a and $b$ as $a$ dark band through the middle of the mixing region. This appears to extend as a separate identifiable region for a downstream distance of at least ten slot heights.

\section{B. PROFILE MEASUREMENTS}

The cone-static and pitot pressure measurements were processed to give distributions of Mach number, total pressure and static pressure across the mixing region. The static pressure was found to be approximately constant across the viscous zone at any given axial station. The case with the largest variations noted is plotted here in Fig. 13, where it can be seen that the maximum deviation from the mean is less than $10 \%$. These results can be interpreted to mean that the boundary layer form of the viscous flow equations can probably be applied to this flow problem within a reasonable level of approximation.

Detailed Mach number profiles are presented in Figs. 14 and 15 . The viscous mixing region is clearly delineated and the effect of the free stream adjustments can be seen at the outer edge of the profiles. The combined effects of viscous forces, axial pressure gradients and gross turning of the flow to make the necessary initial pressure adjustments are displayed here in detail. Finally, with the plausible assumption of constant total temperature, these profiles can be easily converted into velocity profiles. 


\section{WALL SHEAR}

The skin friction balance described before was used to make direct measurements of the wall shear force at the three downstream stations at both flow rates. Several tests were made of each condition, and the results presented here are the mean of values with a variation of approximately $\pm 8 \%$. Extreme care was taken in alignment and set-up in order to reduce errors to a minimum.

The results for the two principal cases considered are shown in Fig. 16. For the matched pressure injection case, the shear shows a slight increase with axial distance. However, for the low mass flow, over expanded pressure case, the shear was found to increase markedly along the wall. This is due to the rapid acceleration of the low speed injectant stream by the viscous work performed by the high speed main stream and the increasing pressure through the recompression zone which is absent for the matched pressure case. It is well to note that the apparently high value of the shear measured at the last axial station for the low injectant rate case is the result of several separate tests where the variation from test to test was less than $5 \%$.

In order to more clearly elucidate the production of the high shear values at the last downstream station for the low mass flow case, the model was re-inserted into the tunnel, and a special test series was run where the shear at that station was determined as a continuous function of mass injection rate over the range from zero to highly underexpanded. A schlieren photograph obtained for a condition of $\mathrm{ps}_{\mathrm{s}} / \mathrm{p}_{1}=1.45$ is shown in Fig. 17. The injectant stream expands to a slightly supersonic condition and then shocks down. This shock is reflected off the lower wall, separating the thin boundary layer, and then passes through the viscous mixing zone. A relatively strong disturbance is also produced on the free stream side of the splitter plate.

The shear results are given in Fig. 18. Note that two headers or manifolds were used in these tests. The first header is the one used throughout this paper, but it would not allow enough mass flow to achieve underexpansion. Therefore, a second header was fabricated with an inlet area of slightly more than three and a half times that of the first header. The data points obtained using this second header are represented with open symbols in Fig. 18. Note the excellent agreement of data as illustrated by the mass flow ratio just slightly greater. than 0.20 .

There is one interesting point illustrated here concerning the effect of the rate of mass injected on the wall shear. In the regime between the two specific cases studied in detail, there is an increase of $100 \%$ in the mass injection rate producing a $120 \%$ decrease in shear. While in the regime between matched flow and the case of underexpanded flow, $\rho_{s} u_{s} / \rho_{1} u_{1}=$ 0.3802 , there is a $90 \%$ increase in mass injected but now with an increase in shear of $35 \%$. This shows that the separation just downstream of the slot due to the reflected shock has had some effect, but that the flow has reattached. Finally, it is interesting to note that the highest values of the shear at 
this most downstream station were for no injection through the slot.

\section{MOMENTUM INTEGRAL ANALYSIS OF THE DATA}

In order to verify the internal consistency of the profile and wall shear measurements, it is instructive to use the profile data and the wall pressure distribution in the integral momentum equation

$$
\frac{\tau_{\mathrm{w}}}{\rho_{2} \mathrm{U}_{2}{ }^{2}}=\frac{\mathrm{d} \theta}{\mathrm{dx}}-\frac{\theta}{1 / 2 \rho_{2} \mathrm{U}_{2}{ }^{2}} \frac{\mathrm{dp}}{\mathrm{dx}}\left[2+\frac{\delta^{*}}{\theta}-\mathrm{M}_{2}{ }^{2}\right]
$$

to infer. the wall shear. Of course, this procedure is subject to considerable uncertainty since it is well known that it is difficult to determine $d \theta / d x$ with sufficient accuracy to produce accurate $\tau_{W}$ results. Indeed, it was just this situation that prompted the initial development of skin friction balances twenty years ago. Nevertheless, a comparison of directly measured wall shear values and those inferred from the momentum integral equation can be useful in adding confidence to the data, especially when the directly measured results are higher than might have been anticipated.

The values of $\theta$ and $\delta^{*}$ determined from the measured Mach number profiles, assuming a constant total temperature, are shown in Fig. 19 for the low mass flow condition. The local slope, $\mathrm{d} \theta / \mathrm{dx}$, was determined by taking straight line segments between the points, including that at the initial station which is not included in Fig. 19, and averaging the slopes of each point. We experimented with various continuous curves drawn through the points and this did effect the results. However, there is a great deal of arbitrariness in the choice of a particular curve, so we have opted for the simple choice of using straight line segments.

The results for the wall shear that were obtained are shown as triangles on Fig. 20, where the directly measured values are also reproduced. It is particularly noteworthy that the values obtained are consistently higher than the directly measured values. While the actual values indicated by the momentum integral approach can be moved around considerably by various choices of a curve for $\theta(x)$ through the data points, no reasonable curve will give $\tau_{w}$ values lower than those measured directly. The uncertainty in determining $\tau_{w}$ from the momentum integral approach using the widely spaced stations where $\theta$ was measured here is large enough that no conclusions should be read into the discrepancy in the shear values obtained by the two methods. The directly measured values are by far the more accurate. However, this exercise with the momentum integral procedure certainly lends strong credence to the high values of wall shear measured with low mass injection rates. 
Detailed flow field measurements, flow visualization results and directly measured wall shear data have been simultaneously obtained for slot injection into a supersonic flow here for the first time. These results should provide a critical standard against which the adequacy of analytical procedures can be tested.

One result of considerable practical importance that was obtained is that for low injection rates through a slot, it is possible to achieve wall shear values higher than would be expected on a flat wall with no slot at all under the same free stream conditions. With increased injection rates, the wall shear then drops substantially below the flat wall values before rising again when the flow out of the slot becomes under-expanded.

Clearly, more work should be performed in this problem area. of particular interest, would be: (1) further data for under expanded injection, (2) results for foreign gas injection, (3) an investigation of the behavior of wall shear at low injection rates, and (4) possible optimization of shear and heat transfer reduction by combining slot and porous wall injection.

\section{APPENDIX A}

In this section, we present estimates of the experimental errors involved in the various measurements. It must be remembered that these are maximum errors and most of the measurements were more accurate than the following analysis indicates. The basic measurements made were pitot and cone static pressures from which the Mach profiles were derived. Therefore let us start the analysis here.

Pitot Pressures.--The errors incurred here were the sum of many smal1 errors since each transducer was individually calibrated. These errors were 1) reading from the strip chart recorders; 2) turbulence in the shear layer; 3) calibration; and 4) response time due to lateral motion. All of these are small and in some instances do not apply, for example the reservoir pitot pressure had no response error. As was estimated in Ref.[10], these measurements were within $\pm 0.5 \%$ of the true value.

Cone Static.--Errors incurred making these measurements were estimated to be slightly less than those incurred for the pitot pressures. This is due to the fact that the gradients encountered were much less and the turbulence level had little effect on the static pressure. However, in order to make a conservative estimate of all errors, the error here will be set at $\pm 0.5 \%$.

Normalized Pressures.--Since the reservoir pressure varied about $2.5 \%$ during these measurements each pressure had to be normalized by its respective reservoir pressure. That is, since an error of $\pm 0.5 \%$ is divided by $\pm 0.5 \%$, the total error is $\pm 1 \%$. However, this normalization 
process involved correlating two pressures in time which induced another $\pm 0.5 \%$ error or a total error of $\pm 1.5 \%$ error for all normalized pressures.

Vertical Position.--The accuracy of the linear potentiometer and strip recorder wire both $\pm 0.1 \%$ for full scale deflection. However, only about $60 \%$ of the maximum deflections were used and aerodynamic loading was determined to be negligible; therefore the vertical position was within $\pm 0.2 \%$ or as much as \pm 0.002 inches.

Pressure Ratios.--Since it was determined the normalized pressures were within $\pm \overline{1.5 \%}$, the ratios without consideration of position would be $\pm 3.0 \%$ of their actual values. Now assuming each normalized pressure was at an opposite extreme, the ratios would be within $\pm 3.4 \%$ of their true values.

Mach Number Profiles.--Since the pressure ratios used to determine

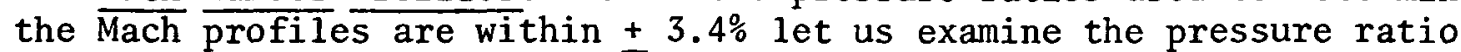
$\mathrm{p}_{\mathrm{c}} / \mathrm{p}_{0}^{\prime}=0.1860$ which gives a $\bar{M}$ ach number of 2.40 .

$$
\begin{array}{ll}
(+3.4 \%) \frac{\mathrm{p}_{\mathrm{c}}}{\mathrm{p}_{\mathrm{o}}^{\prime}}=0.1932 & \mathrm{M}=2.34(-2.5 \%) \\
(-3.4 \%) \frac{\mathrm{p}_{\mathrm{c}}}{\mathrm{p}_{\mathrm{o}}^{\prime}}=0.1796 & \mathrm{M}=2.46(+2.5 \%)
\end{array}
$$

Hence an error in the pressure ratios of $\pm 3.4 \%$ yields Mach number within $\pm 2.5 \%$.

Skin Friction.--The estimates of Ref. (10) apply here which indicate that the error due to the skin friction balance are $+6 \%$ due to tunnel noise, amplifiers, and recorders. Also, from Ref. ( $\overline{1} 1)$, an additional error of $+1 \%$ due to misalignment of the floating element should be added yie $\overline{1}$ ding an error of $\pm 7 \%$.

\section{REFERENCES}

1. Visich, Jr., M., and Libby, P. A., "Experimental Investigation of Mixing of Mach number 3.95 Stream in Presence of Wa11", NASA TN D-247, Feb. 1960.

2. McRee, D. I., Peterson, J. B., and Braslow, A. L., "Effect of Air Injection Through a Porous Surface and Through Slots on Turbulent Skin Friction at Mach 3", NSAS TN D-2427, Aug. 1964.

3. Goldstein, R. J., Eckert, E. R. G., Tsou, R. K. and Haji-Sheikh, A., "Film Cooling with Air and Helium Injection Through a Rearward-Facing Slot into a Supersonic Air Flow", AIAA Journa1, Vol. 4, No. 6, 1966, pp. 981-985. 
4. Gilreath, H. E. and Schetz, J. A., "A Study of Tangential Slot Injection in Supersonic Flow", AIAA Journal, Vol. 5, No. 12, 1967 , pp. 2149-2154.

5. Schetz, J. A., Gilreath, H. E. and Lubard, S. C., "Fuel Injection and Mixing in a Supersonic Stream", Twelfth Symposium on Combustion, 1969.

6. Cary, A. M. and Hefner, J. N., "An Investigation of Film Cooling Effectiveness and Skin Friction in Hypersonic Turbulent Flow", AIAA Paper No. 70, June, 1971.

7. Brund, Yanta, and Risher, "Balance for Measuring Skin Friction in the Presence of Heat Transfer", NOLTR 69-59, 10 June 1969.

8. Sims, J. L., Tables for Supersonic Flow Around Right Circular Cones at Zero Angle of Attack, NASA SP-3004, 1964.

9. Equations, Tables, and Charts for Compressible Flow, NACA 1135 , 1953.

10. Waltrup, P. J. and Schetz, J. A., "An Experimental Investigation of a Compressible Boundary Layer Subjected to a Systematic Variation of Adverse Pressure Gradient", VPI-E-71-18, August 1971.

11. O'Donne11, F. B. and Westkaemper, J. C., 'Measurements of Errors caused by Misalignment of Floating-Element Skin-Friction Balances", AIAA Journa1, Vol. 3, Number 1, January 1965. 


\begin{tabular}{|c|c|c|c|c|c|}
\hline & 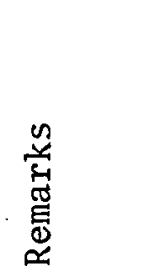 & 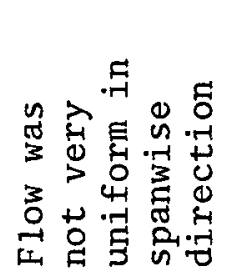 & 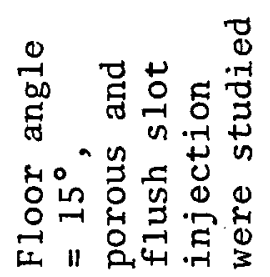 & 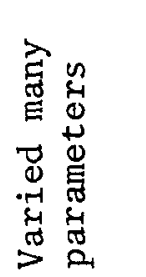 & 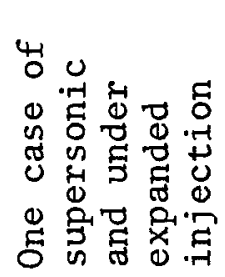 \\
\hline & 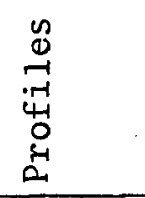 & $0^{0}$ & مे & 志 & ㅇ \\
\hline & 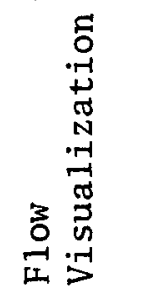 & 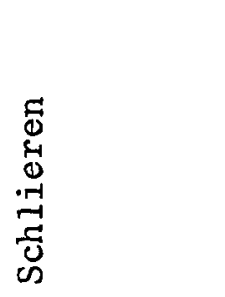 & 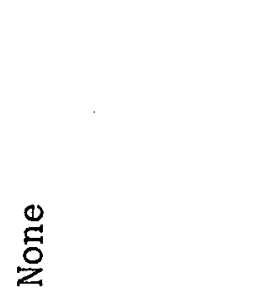 & 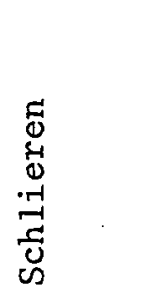 & 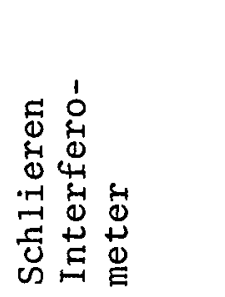 \\
\hline 孞 & 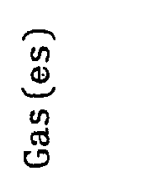 & $\frac{i}{2}$ & $\stackrel{H}{Z}$ & 索臬 & $\stackrel{4}{2}$ \\
\hline $\begin{array}{l}\text { Z゙ } \\
\dot{z}\end{array}$ & $F$ & $\stackrel{\circ}{z}$ & 울 & $\stackrel{0}{2}$ & 운 \\
\hline 点 & $u^{4+1}$ & 울 & $\begin{array}{l}* \\
y \\
0\end{array}$ & 울 & 을 \\
\hline 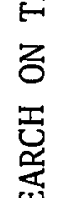 & $\begin{array}{l}z^{n} \\
a^{n} \\
a^{-1} \\
a^{-1}\end{array}$ & $\sum_{\substack{v \\
v}}^{N}$ & i & 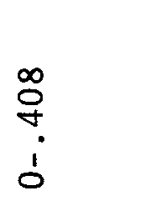 & $\begin{array}{l}\dot{\theta} \\
i \\
0\end{array}$ \\
\hline 㟧 & $\Sigma^{-1}$ & $\begin{array}{l}\text { मू } \\
\dot{m}\end{array}$ & $\begin{array}{l}0 \\
\dot{m}\end{array}$ & $\begin{array}{l}\overrightarrow{0} \\
\dot{n}\end{array}$ & $\begin{array}{l}\infty \stackrel{\Omega}{\sim} \\
\dot{\sim} \dot{8}\end{array}$ \\
\hline 㕵 & $\underset{\stackrel{D}{ \pm}}{\stackrel{\infty}{0}}$ & 융 & 吉 & $\begin{array}{l}0 \\
\text { ğ }\end{array}$ & $\hat{\sigma}$ \\
\hline$<$ & $\stackrel{4}{\ddot{\alpha}} \dot{0}$ & - & $N$ & $m$ & \\
\hline & 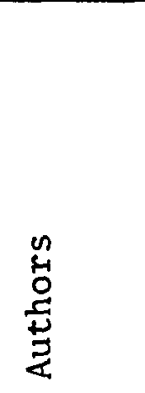 & 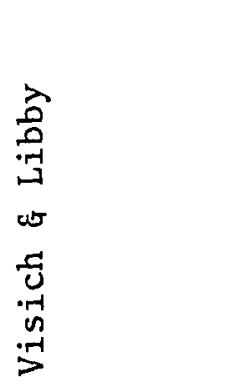 & 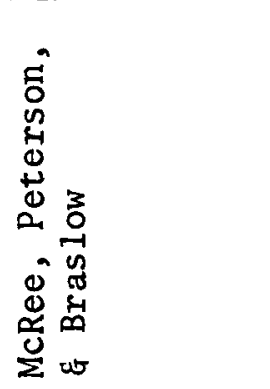 & 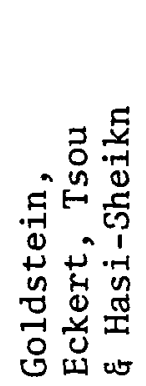 & 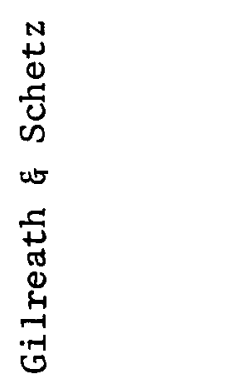 \\
\hline
\end{tabular}




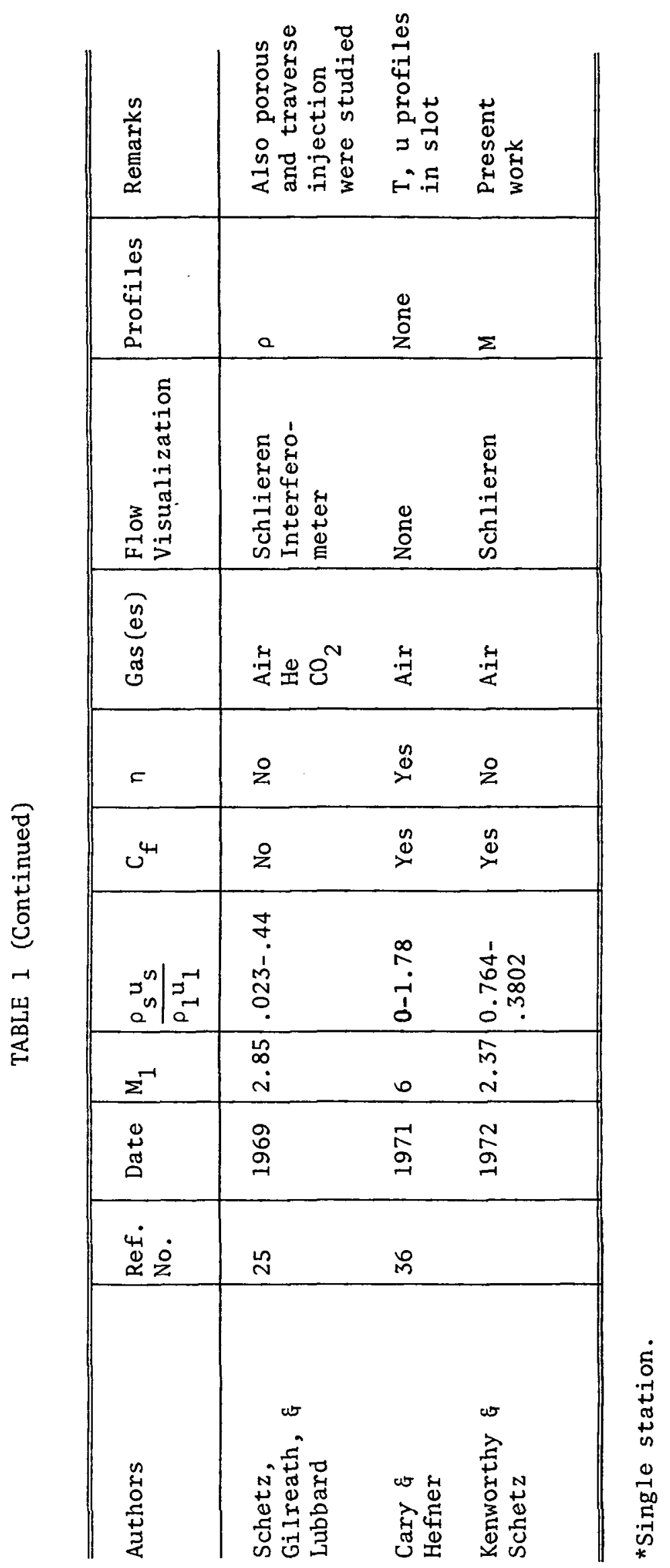


TABLE A-1

ESTIMATE OF ERRORS IN MEASURED AND CALCULATED QUANTITIES

Quantity

Pitot Pressure

Cone Static Pressure

Normalized Pressure

Vertical Position

Pressure Ratios

Mach Numbers

Skin Friction
Estimated Error

$\pm 0.50 \%$

$\pm 0.50 \%$

$+1.5 \%$

\pm 0.002 inch

$+3.4 \%$

$\pm 2.5 \%$

$\pm 7.0 \%$ 


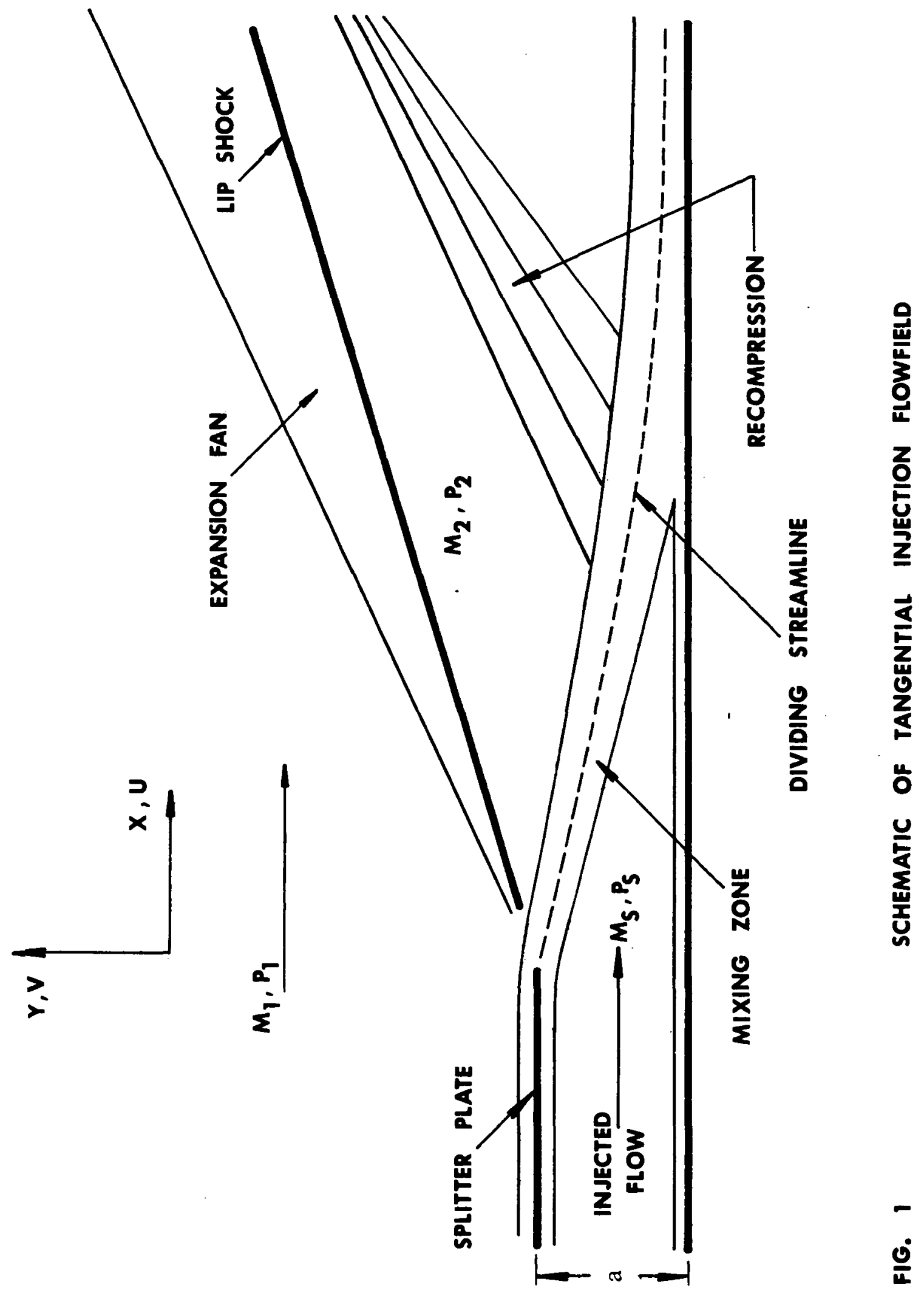




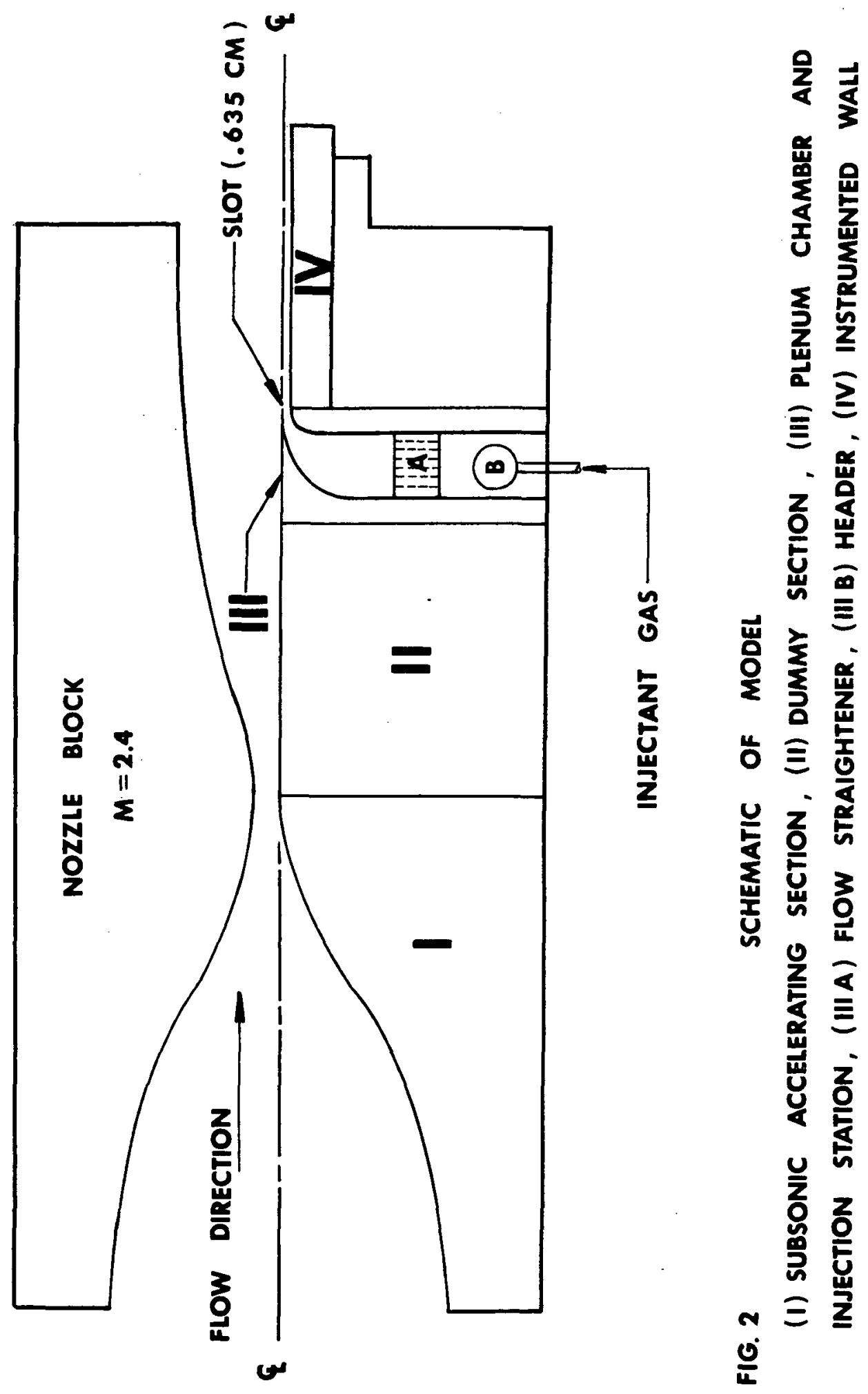




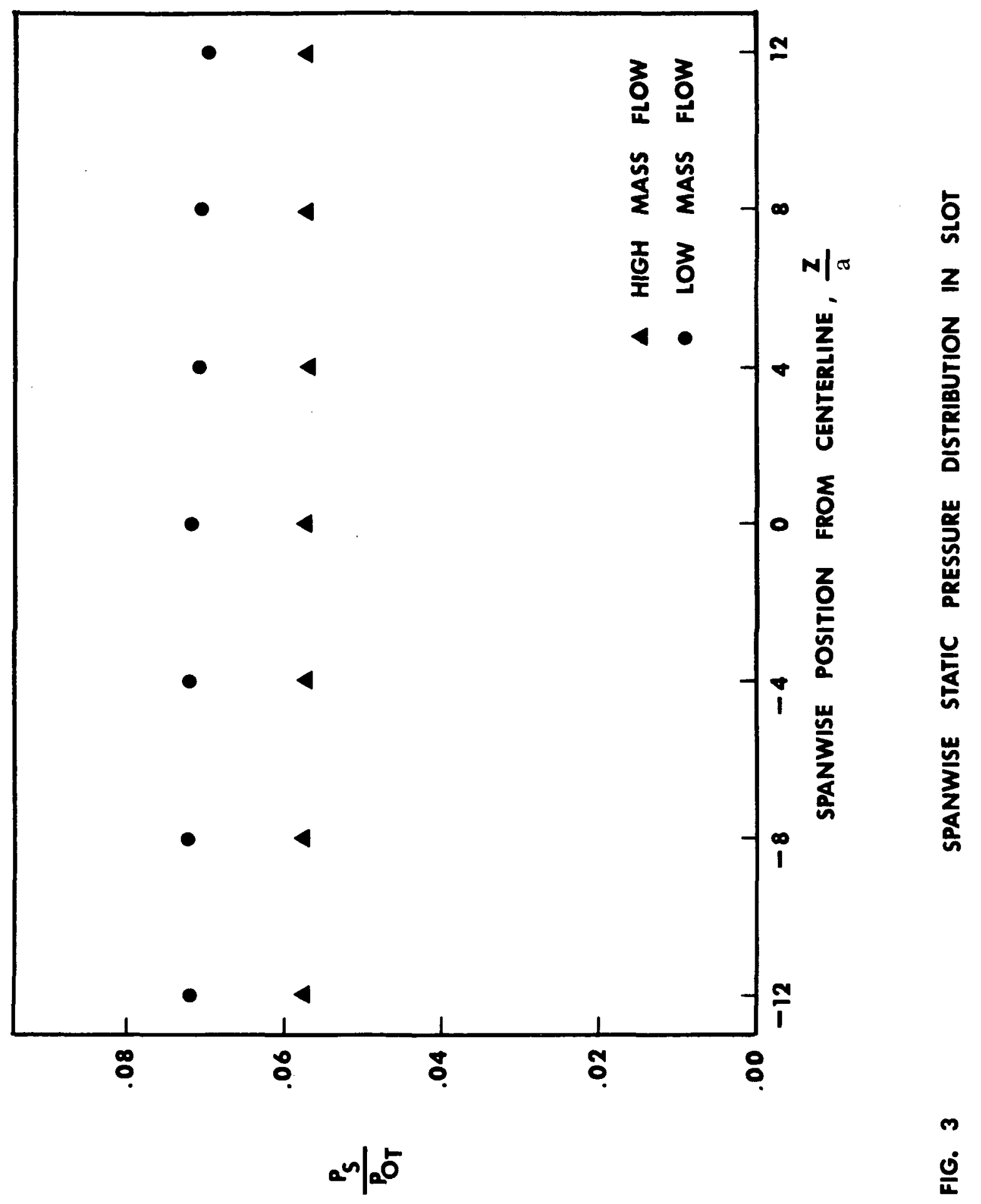




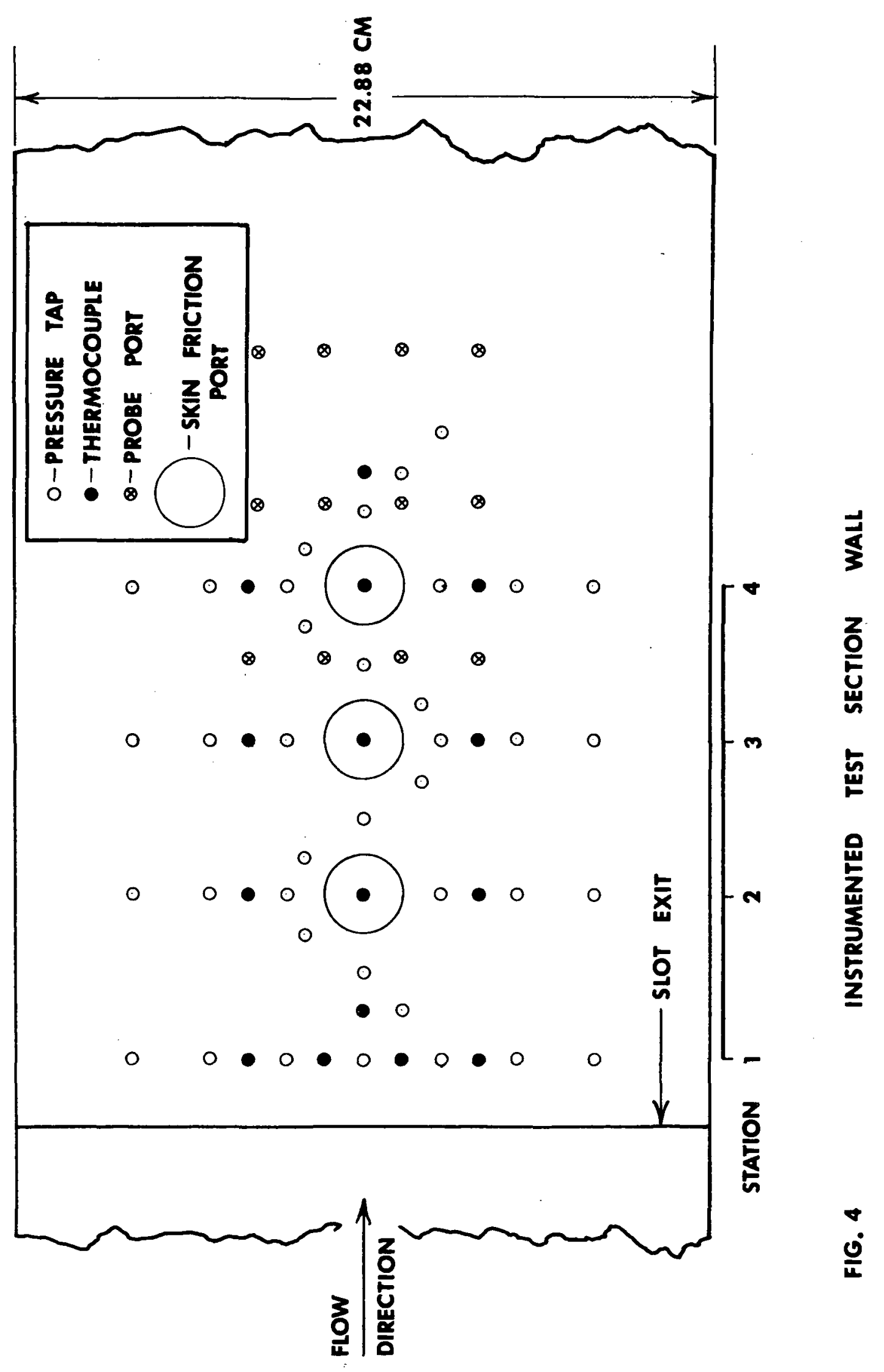




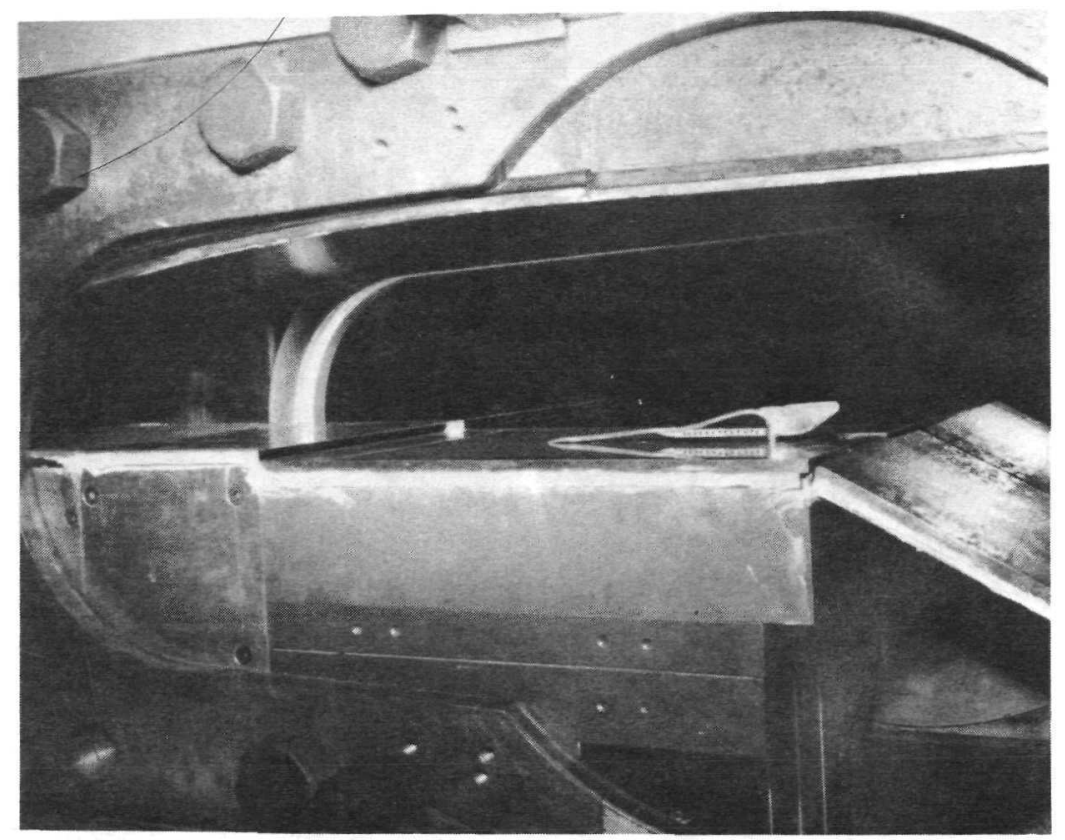

a) MODEL

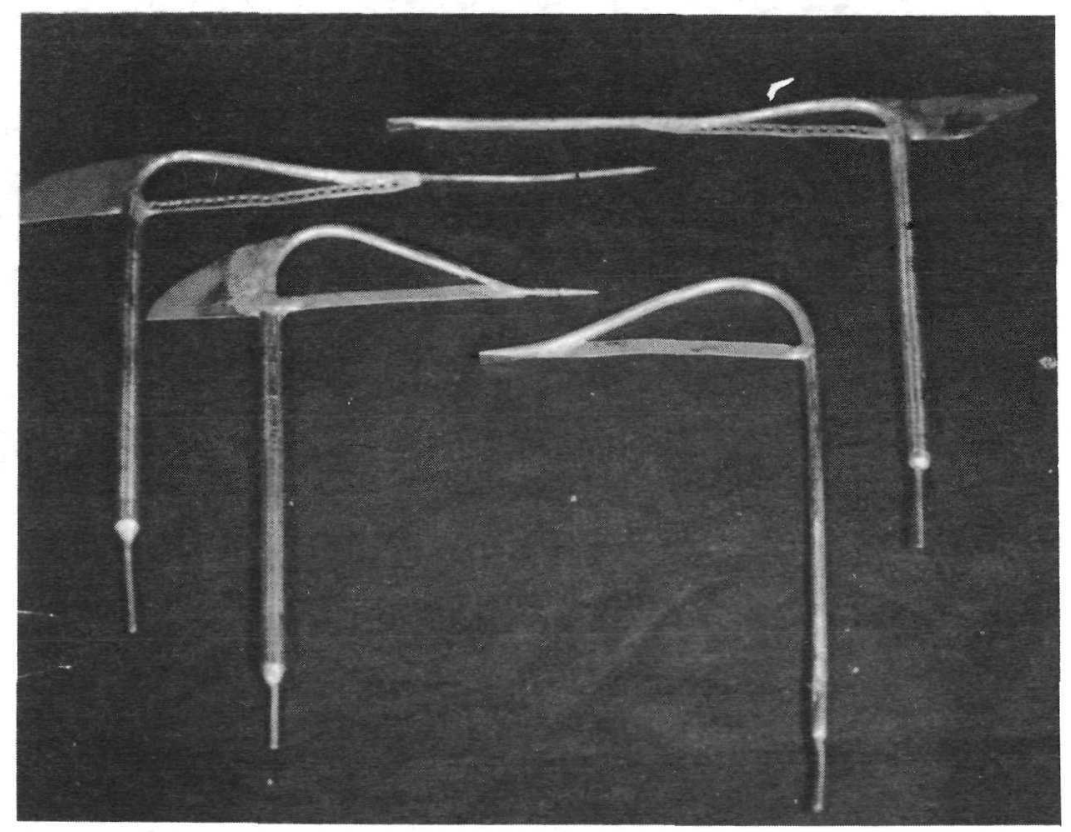

b) PROBES

FIG. 5 PHOTOGRAPHS OF APPARATUS 


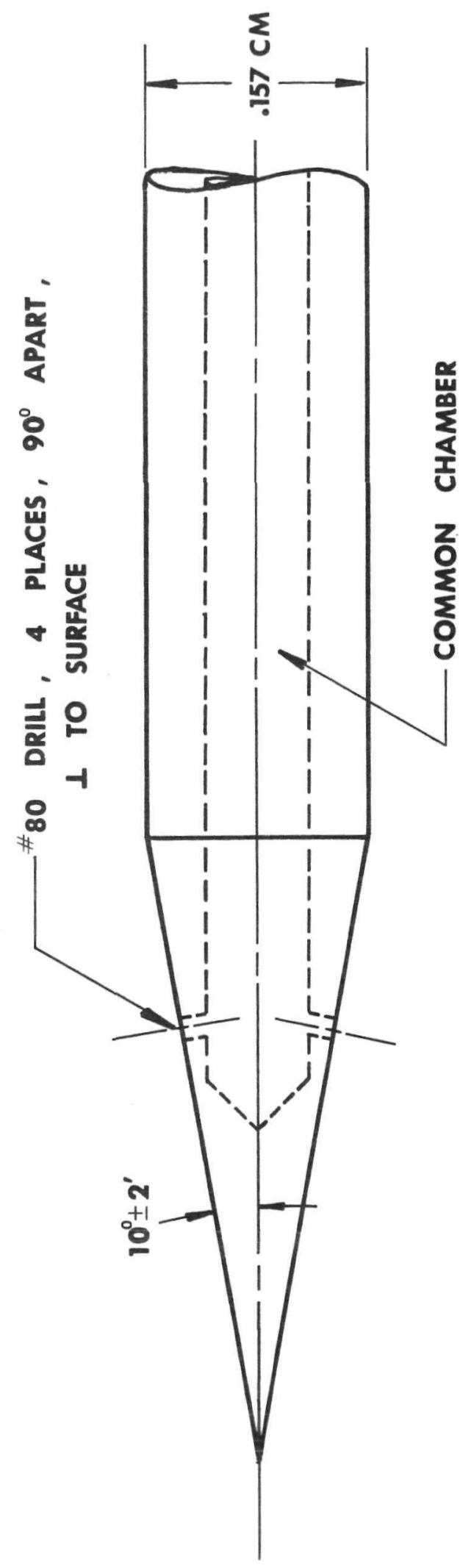

$\frac{\omega}{0}$

불

$\frac{0}{6}$

$\frac{2}{0}$

๘

$\frac{u}{\frac{1}{5}}$

0 


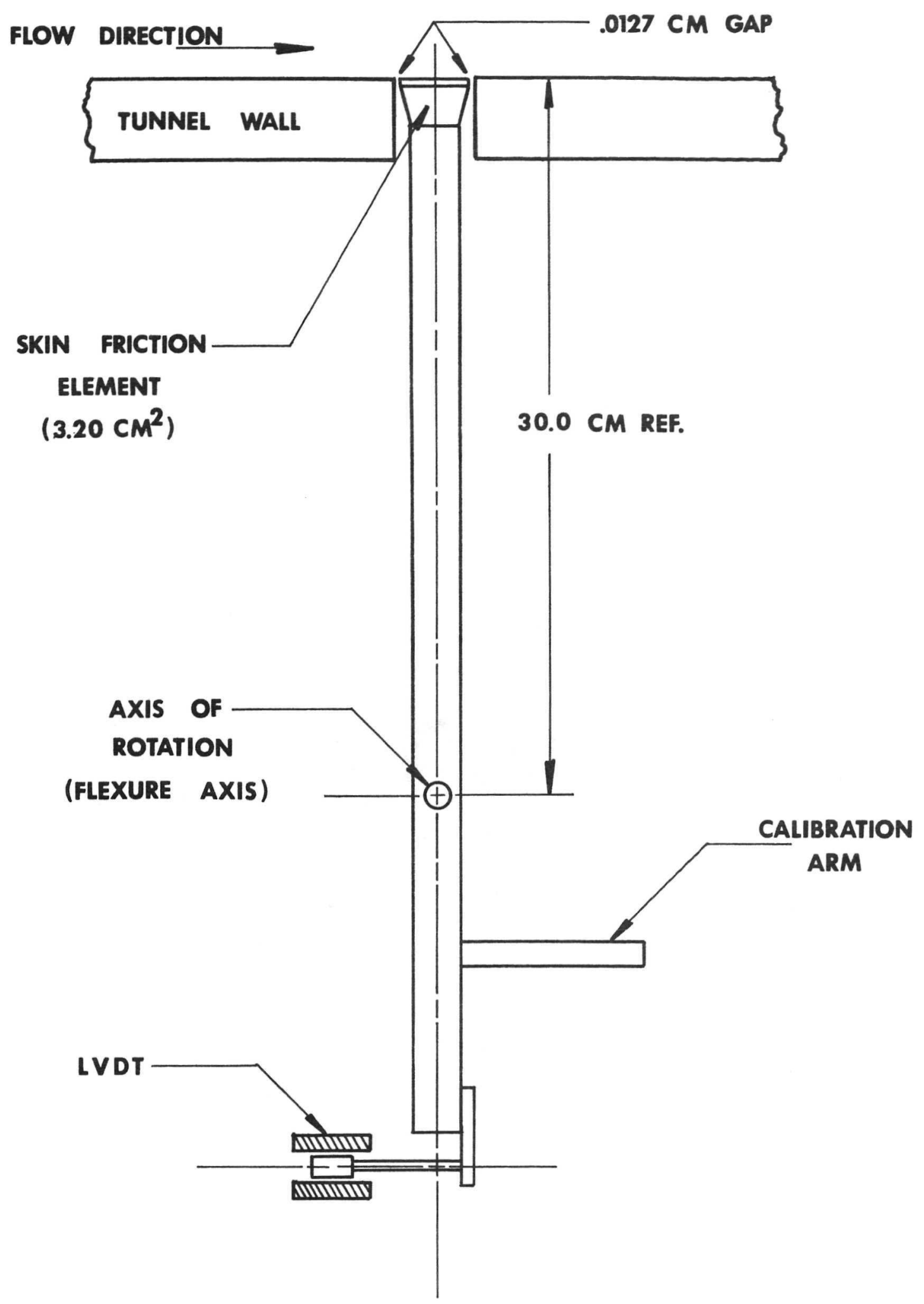

FIG. 7

SCHEMATIC OF SKIN FRICTION BALANCE 


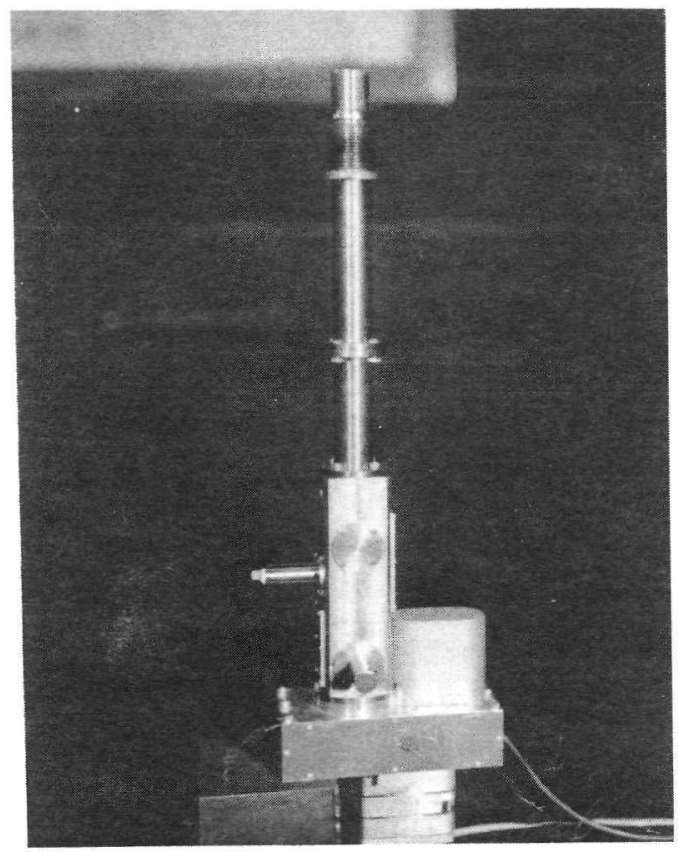

a) THE BALANCE

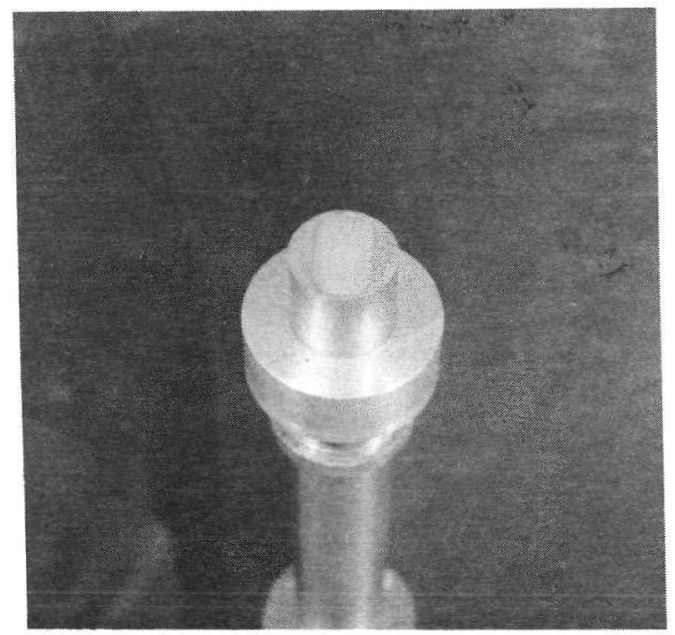

b) CLOSE-UP OF FRICTION ELEMENT

FIG. 8 PHOTOGRAPHS OF SKIN FRICTION BALANCE 


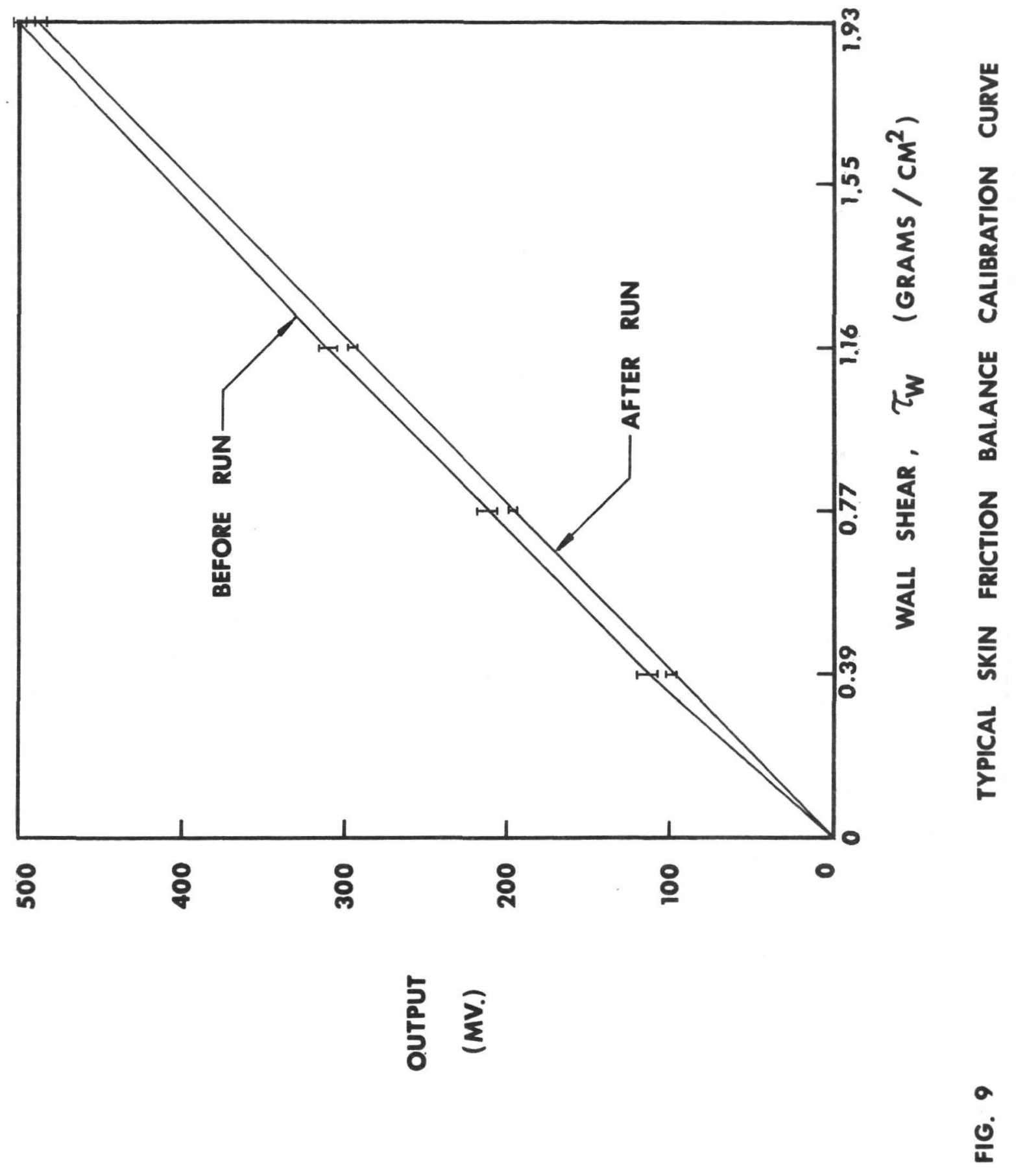




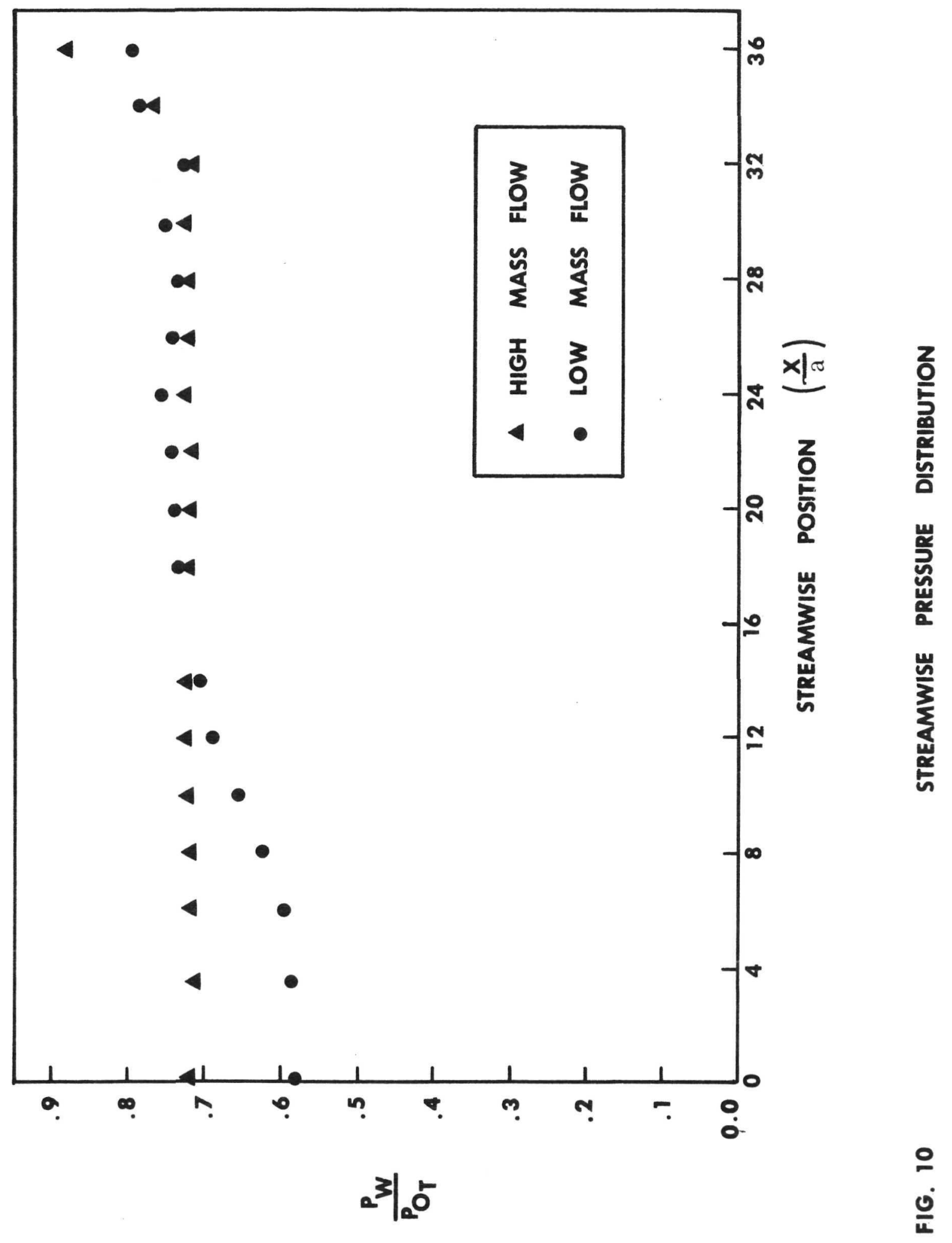




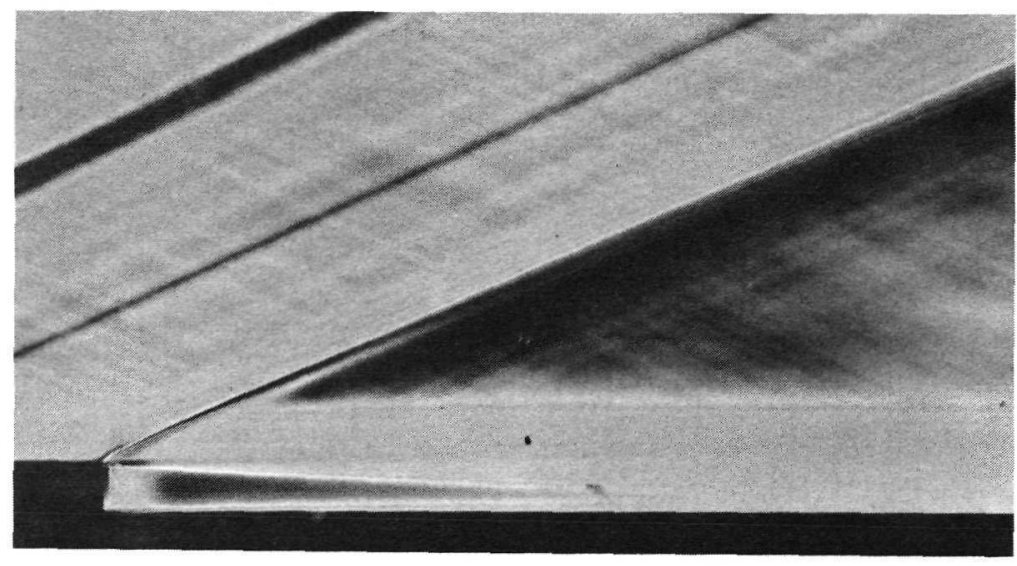

a) HIGH MASS FLOW

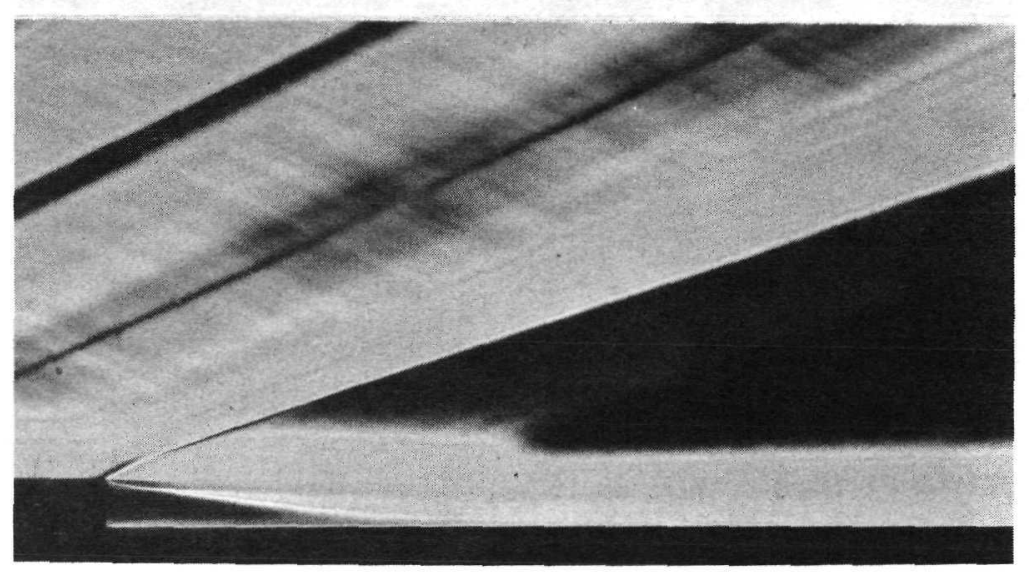

b) LOW MASS FLOW

FIG. 11

SCHLIEREN PHOTOGRAPHS 
a) HIGH MASS FLOW

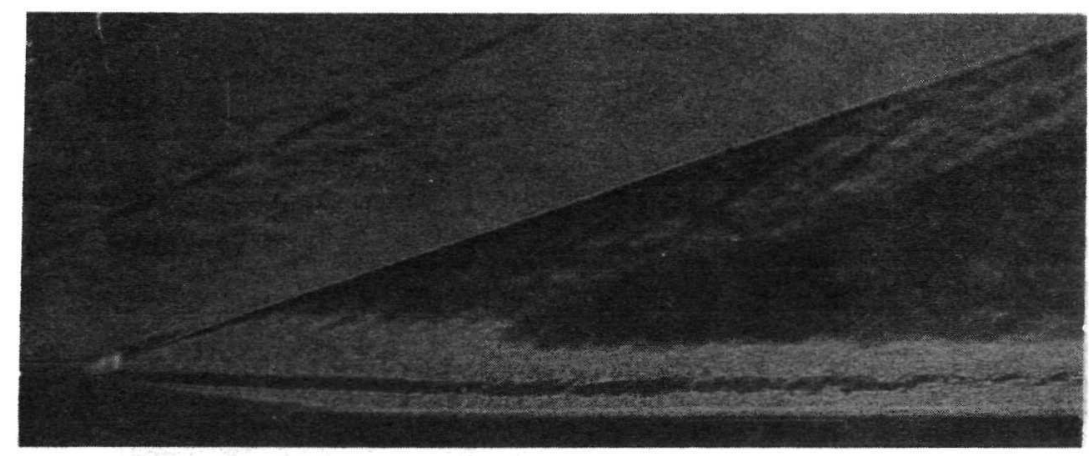

b) LOW MASS FLOW

\section{FIG. 12 SPARK SCHLIEREN PHOTOGRAPHS}




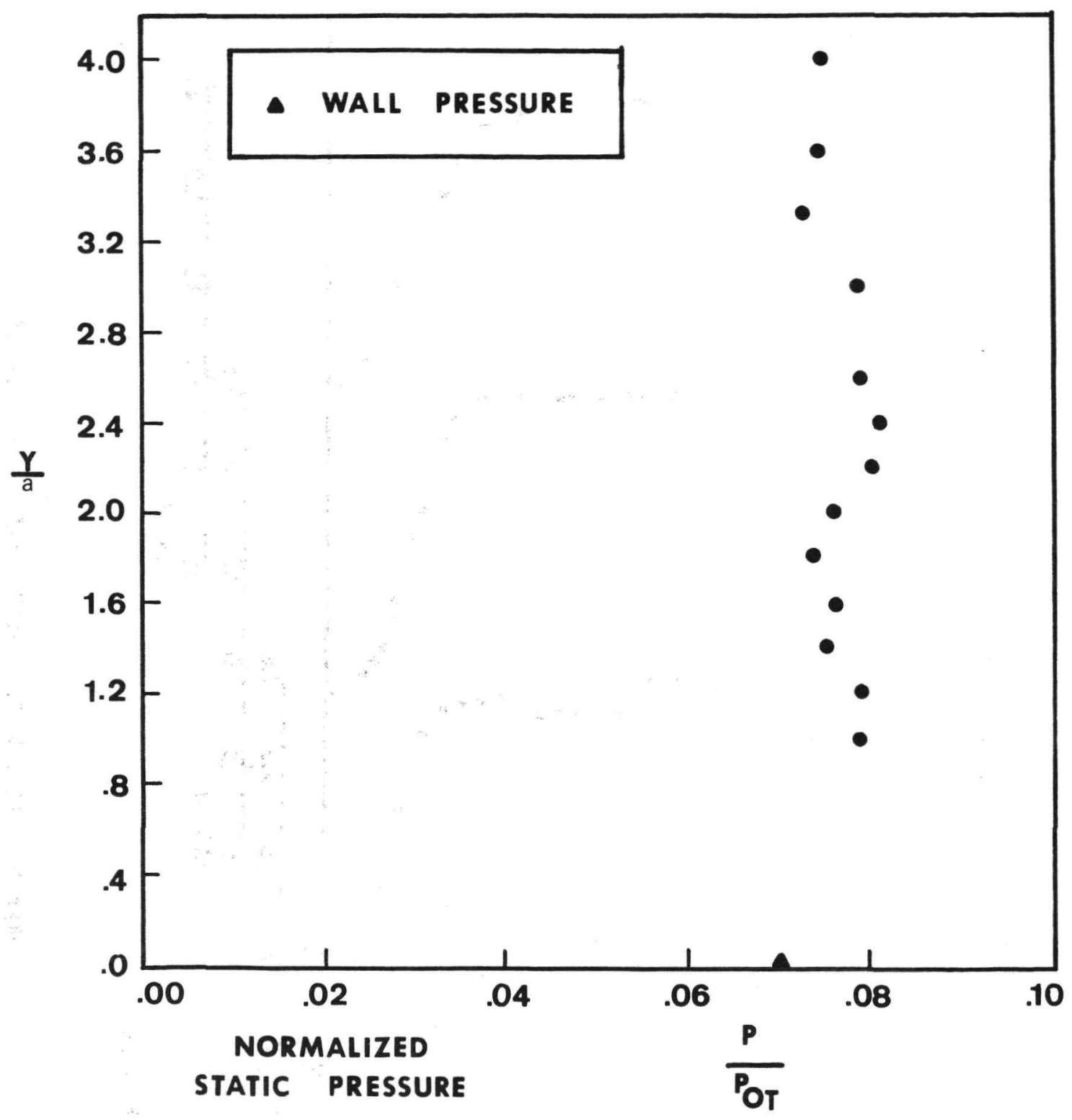

FIG. 13 STATIC PRESSURE PROFILE AT STATION TWO HIGH MASS FLOW RATE 


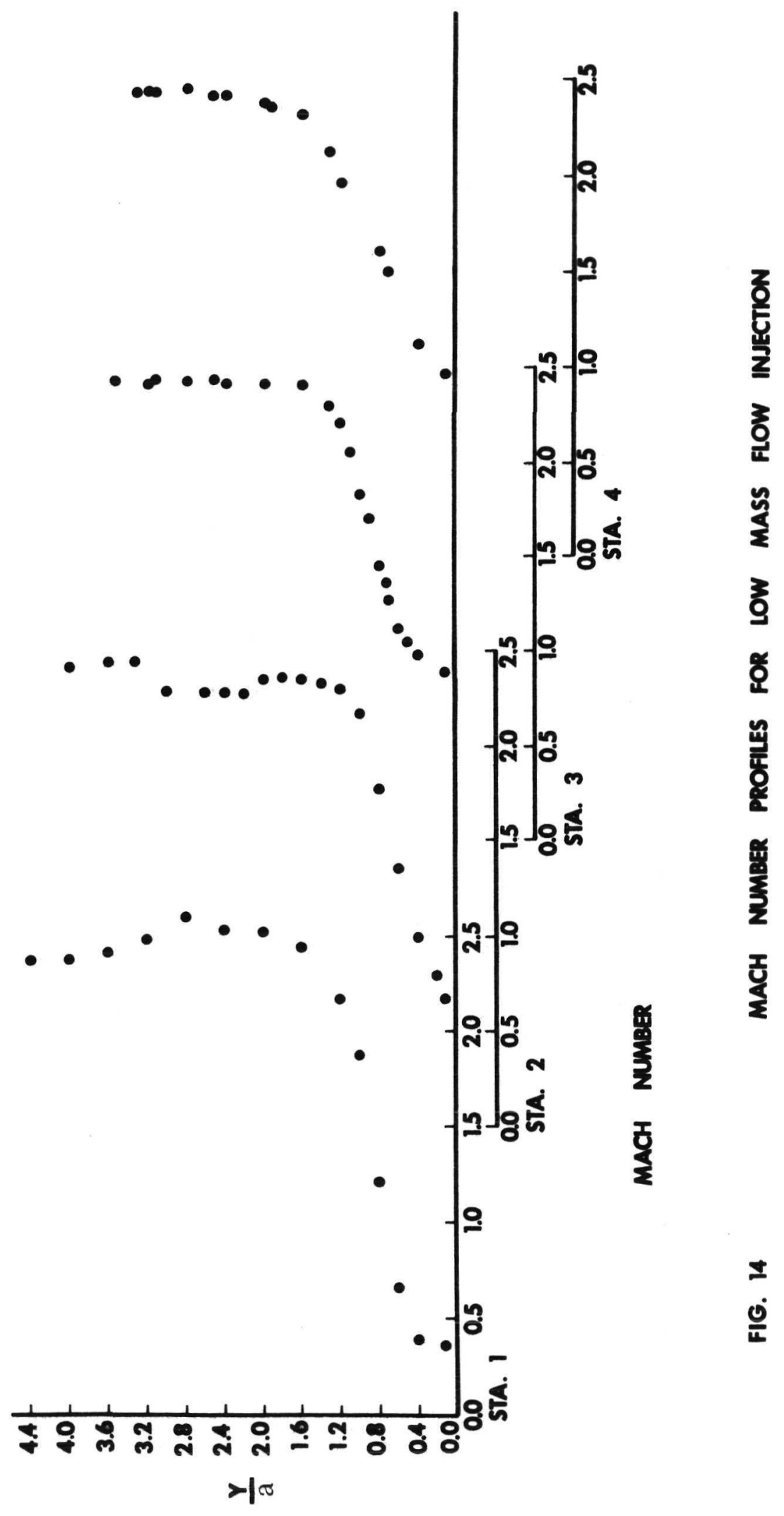




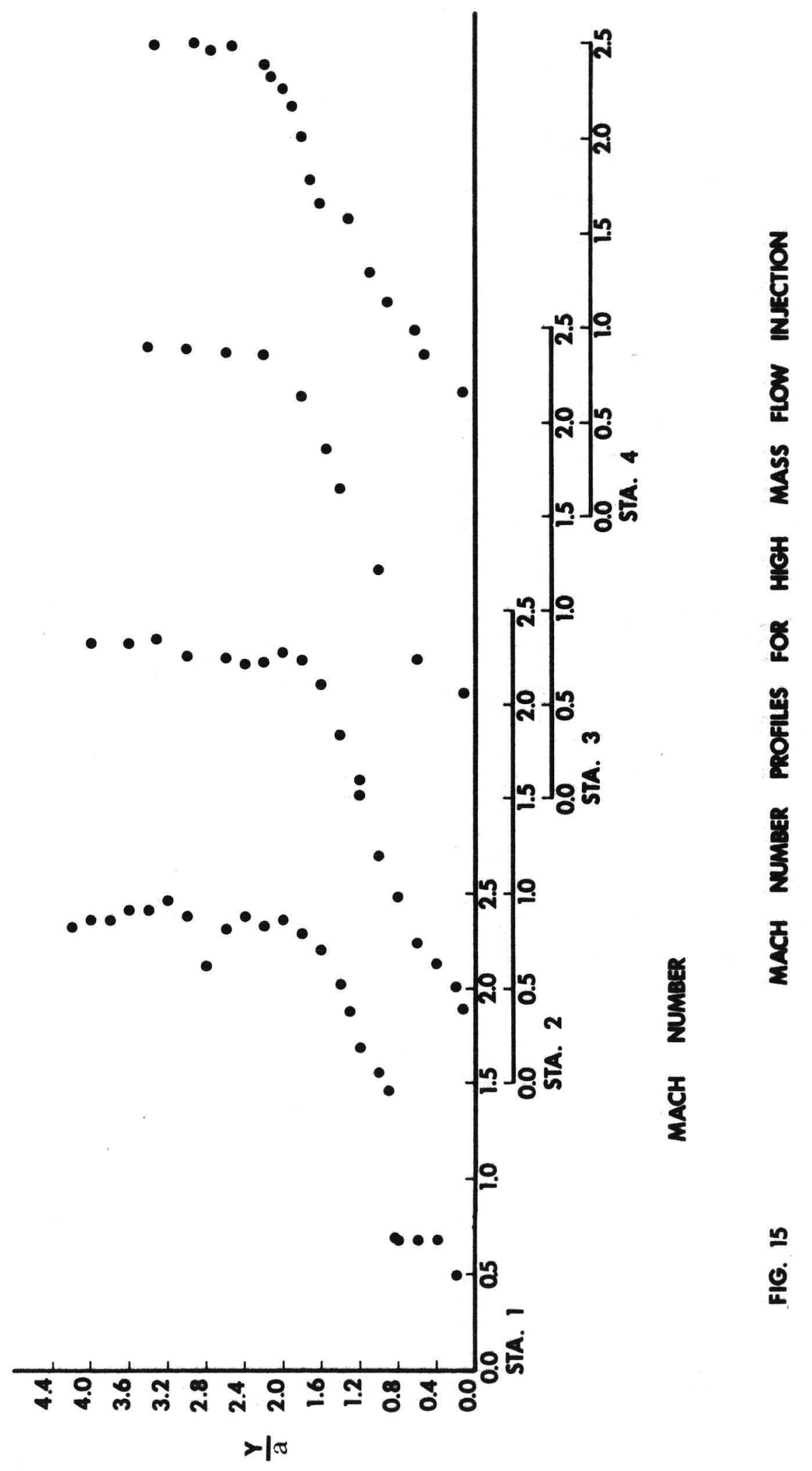




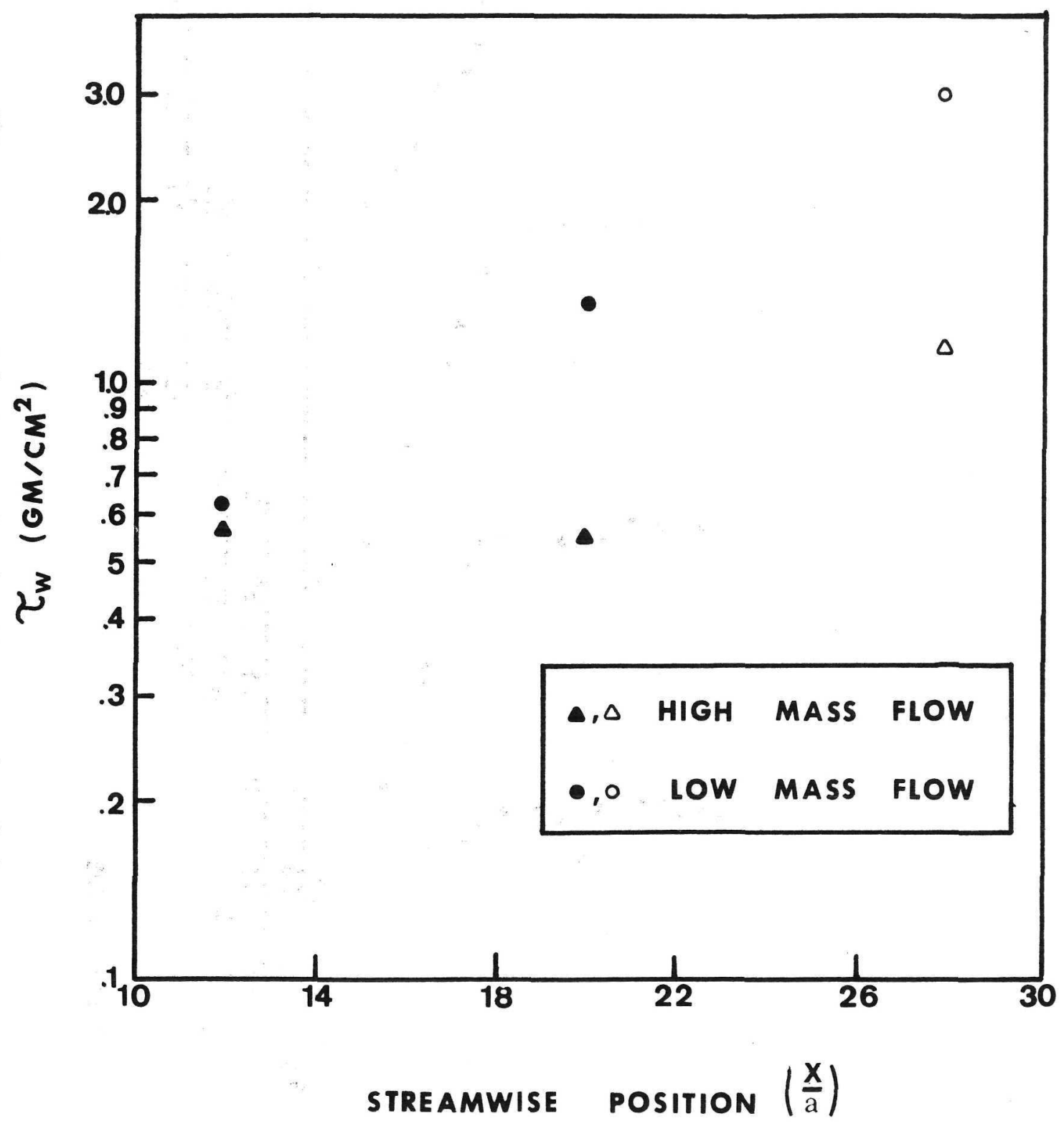

FIG. 16 STREAMWISE SHEAR DISTRIBUTION 


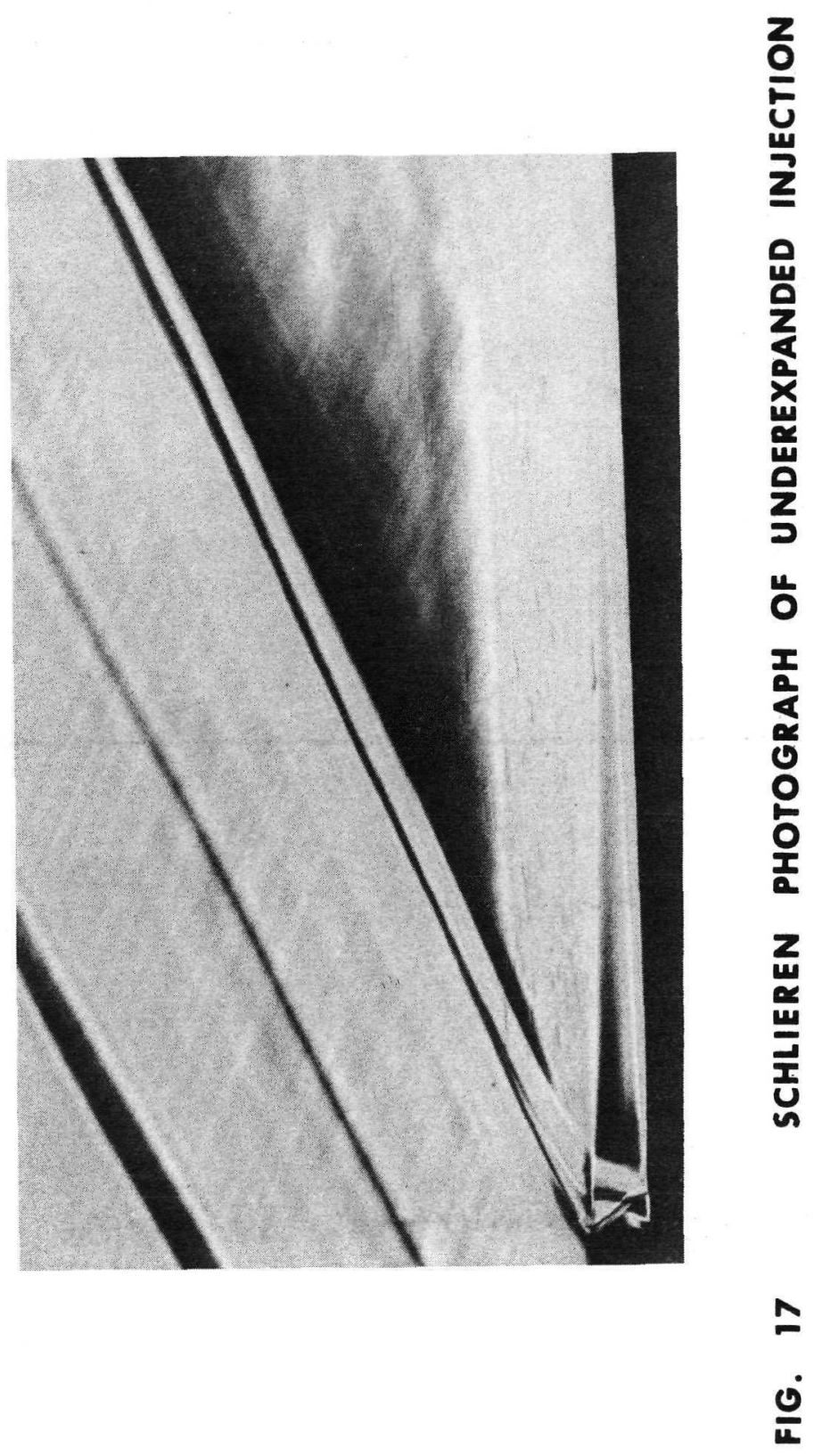




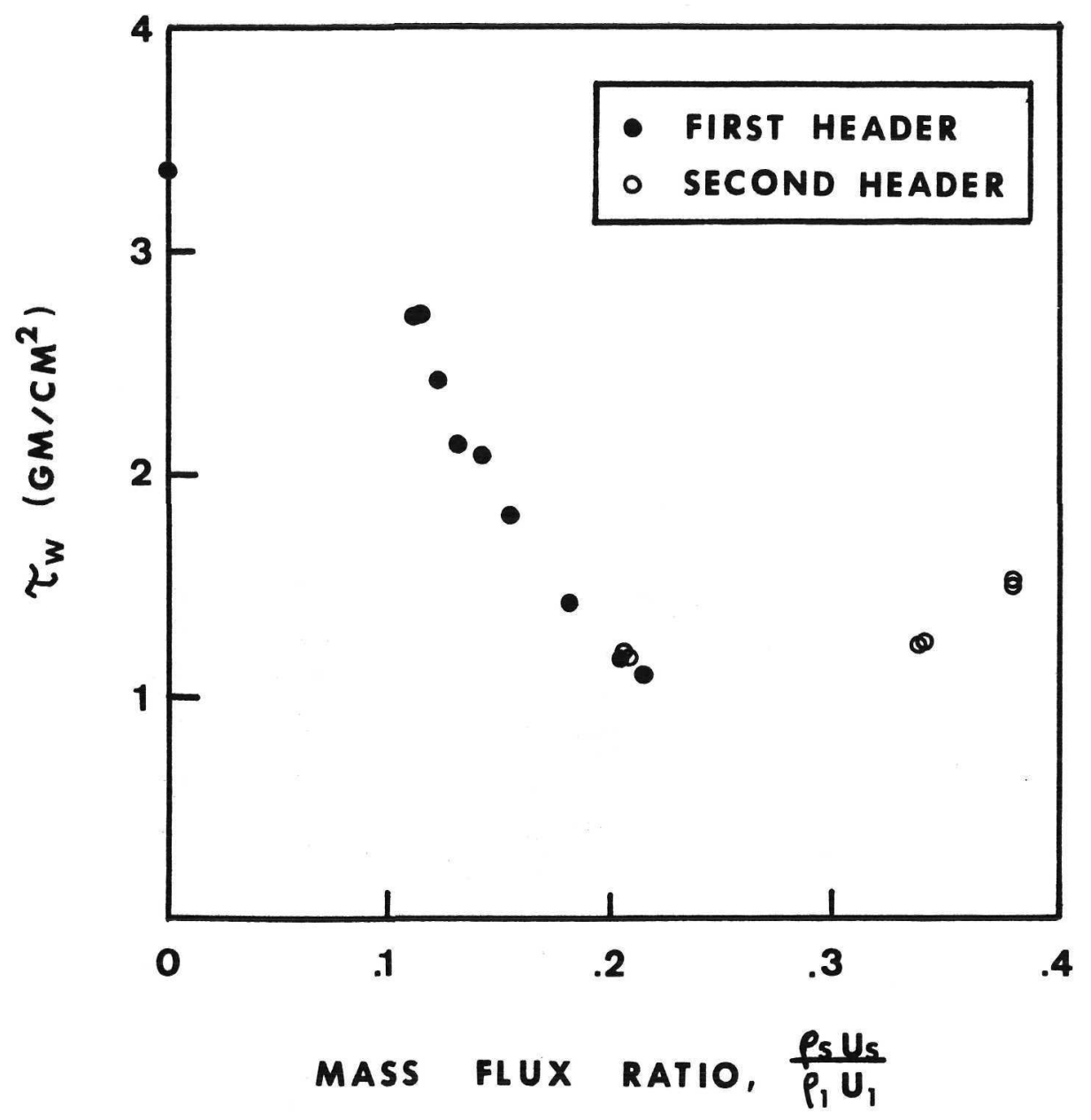

FIG. 18 SHEAR VS. MASS FLUX RATIO AT STATION FOUR 


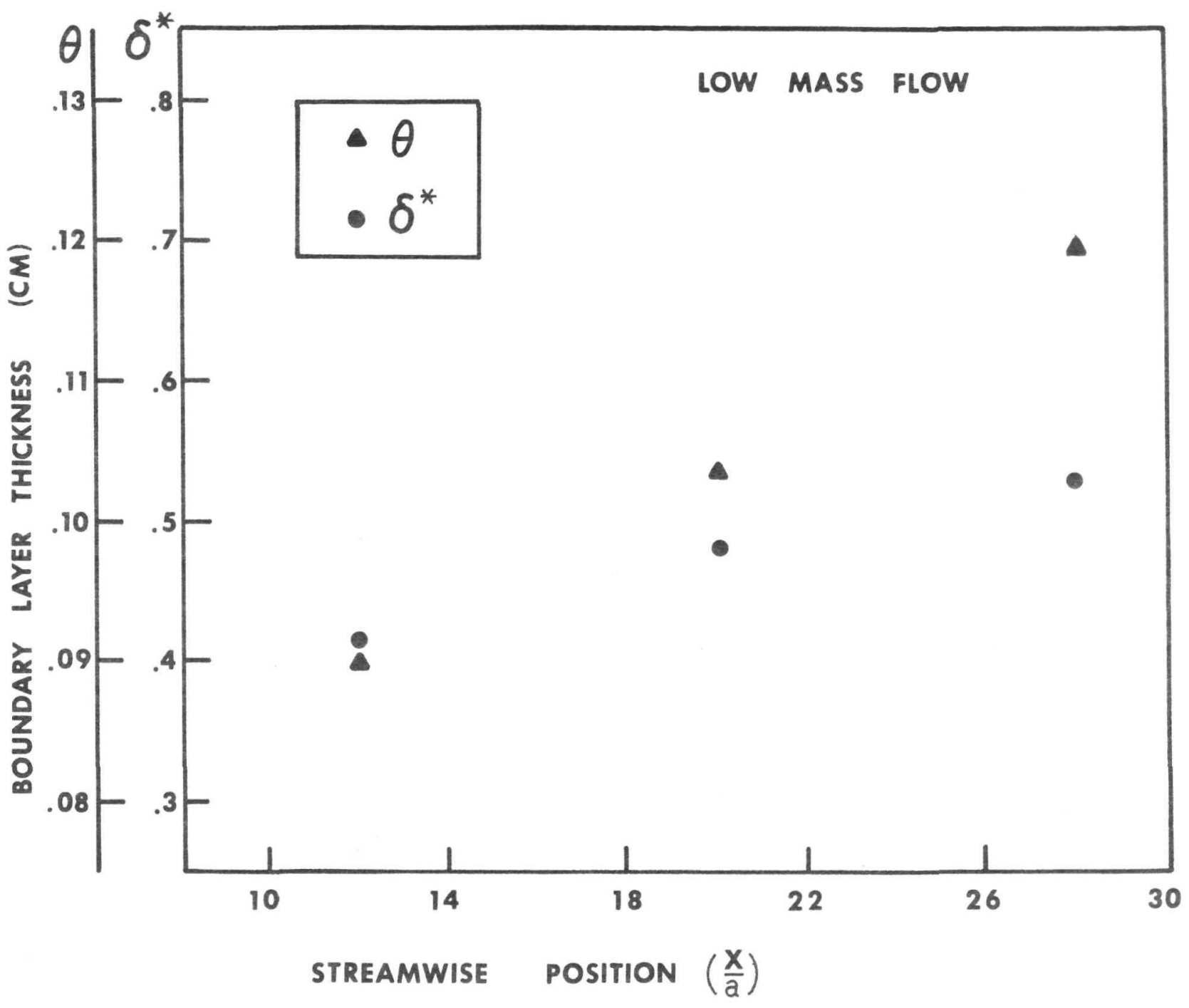

FIG. 19 INTEGRAL BOUNDARY LAYER THICKNESS 


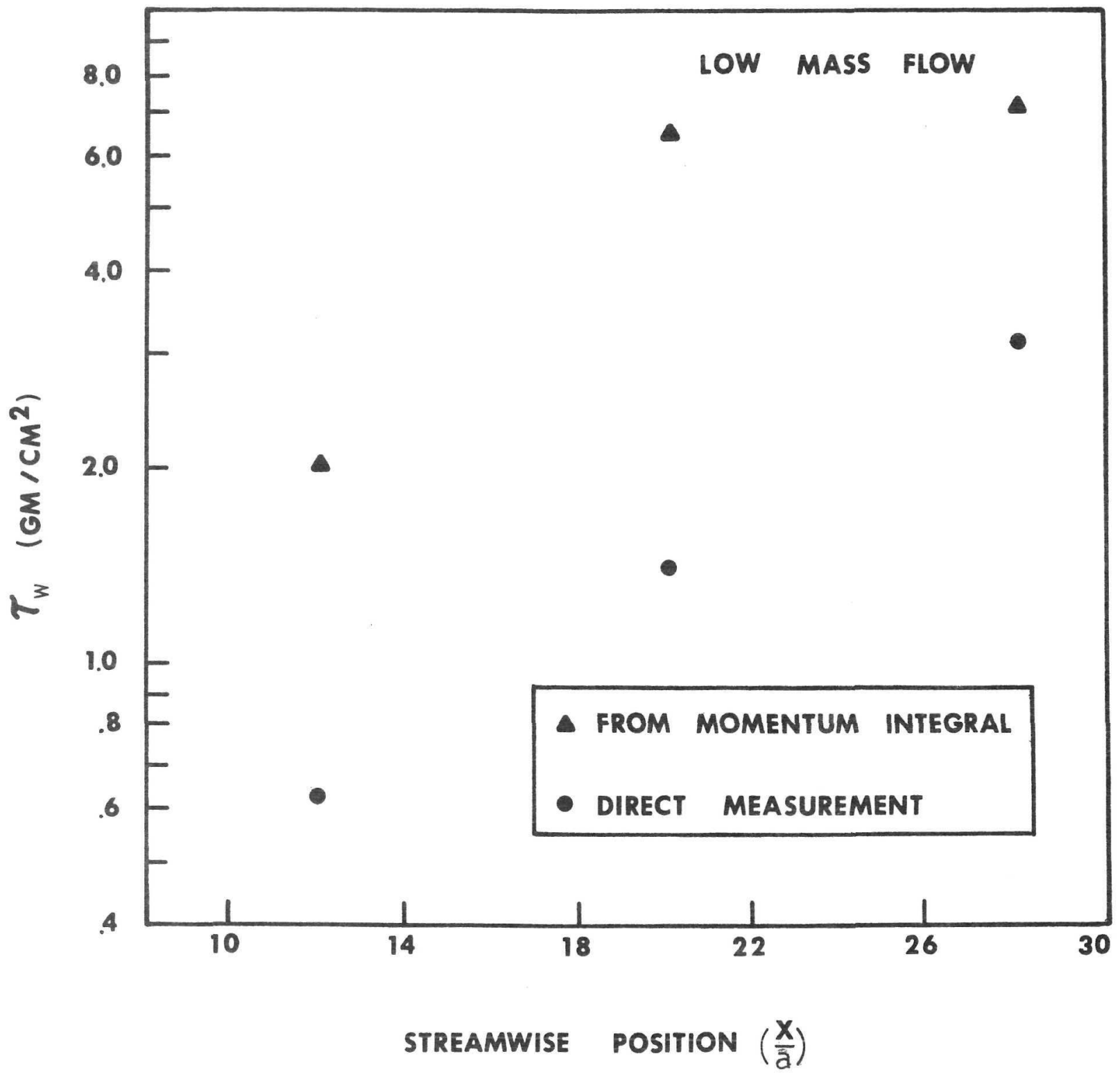

FIG. 20

WALL SHEAR FROM MOMENTUM INTEGRAL 
"The deronautical and space activities of the United States shall be conducted so as to contribute ... to the expansion of human knowledge of phenomena in the atmosphere and space. The Administration shall provide for the widest practicable and appropriate dissemination of information concerning its activities and the results thereof."

-National Aeronautics and Space ACt of 1958

\section{NASA SCIENTIFIC AND TECHNICAL PUBLICATIONS}

TECHNICAL REPORTS: Scientific and technical information considered important, complete, and a lasting contribution to existing knowledge.

TECHNICAL NOTES: Information less broad in scope but nevertheless of importance as a contribution to existing knowledge.

TECHNICAL MEMORANDUMS:

Information receiving limited distribution because of preliminary data, security classification, or other reasons. Also includes conference proceedings with either limited or unlimited distribution.

CONTRACTOR REPORTS: Scientific and technical information generated under a NASA contract or grant and considered an important contribution to existing knowledge.
TECHNICAL TRANSLATIONS: Information published in a foreign language considered to merit NASA distribution in English.

SPECIAL PUBLICATIONS: Information derived from or of value to NASA activities. Publications include final reports of major projects, monographs, data compilations, handbooks, sourcebooks, and special bibliographies.

\section{TECHNOLOGY UTILIZATION} PUBLICATIONS: Information on technology used by NASA that may be of particular interest in commercial and other non-aerospace applications. Publications include Tech Briefs, Technology Utilization Reports and Technology Surveys.

Defails on the availability of these publications may be obtained from:

\section{SCIENTIFIC AND TECHNICAL INFORMATION OFFICE}

\section{NATIONAL AERONAUTICS AND SPACE ADMINISTRATION}

Washington, D.C. 20546 